\title{
Viability and management of the Asian elephant (Elephas maximus) population in the Endau Rompin landscape, Peninsular Malaysia
}

\author{
Salman Saaban ${ }^{1}$, Abd Rasid Samsudin ${ }^{1}$, Mohd Nawayai Yasak ${ }^{1}$, Melvin Gumal $^{2}$, Aris Oziar ${ }^{2}$, Francis Cheong ${ }^{3}$, \\ Zaleha Shaari $^{4}$, Martin Tyson ${ }^{5}$, Simon Hedges ${ }^{\text {Corresp. } 5}$ \\ ${ }^{1}$ Department of Wildlife and National Parks (DWNP), Ministry of Water, Land and Natural Resources, Kuala Lumpur, Malaysia \\ 2 Malaysia Program, Wildlife Conservation Society (WCS), Kuching, Sarawak, Malaysia \\ 3 Johor National Parks Corporation (JNPC), Kota Iskandar, Johor, Malaysia \\ 4 Department of Town and Country Planning (DTCP), Kuala Lumpur, Malaysia \\ ${ }^{5}$ Global Conservation Programs, Wildlife Conservation Society (WCS), Bronx, New York, United States of America \\ Corresponding Author: Simon Hedges \\ Email address: simonhedges@asianarks.org
}

The need for conservation scientists to produce research of greater relevance to practitioners is now increasingly recognized. This study provides an example of scientists working alongside practitioners and policy makers to address a question of immediate relevance to elephant conservation in Malaysia and using the results to inform wildlife management policy and practice including the National Elephant Conservation Action Plan for Peninsular Malaysia. Since ensuring effective conservation of elephants in the Endau Rompin Landscape (ERL) in Peninsular Malaysia is difficult without data on population parameters we (1) conducted a survey to assess the size of the elephant population, (2) used that information to assess the viability of the population under different management scenarios including translocation of elephants out of the ERL (a technique long used in Malaysia to mitigate human-elephant conflict (HEC)), and (3) assessed a number of options for managing the elephant population and HEC in the future. Our dung-count based survey in the ERL produced an estimate of $135(95 \% \mathrm{Cl}=[80,225])$ elephants in the $2500 \mathrm{~km}^{2}$ area. The population is thus of national significance, containing possibly the second largest elephant population in Peninsular Malaysia, and with effective management elephant numbers could probably double. We used the data from our survey plus other sources to conduct a population viability analysis to assess relative extinction risk under different management scenarios. Our results demonstrate that the population cannot sustain even very low levels of removal for translocation or anything other than occasional poaching. We describe, therefore, an alternative approach, informed by this analysis, which focuses on in situ management and non-translocation-based methods for preventing or mitigating HEC. The recommended approach includes an increase in law enforcement to 
protect the elephants and their habitat, maintenance of habitat connectivity between the ERL and other elephant habitat, and a new focus on adaptive management. 


\section{Viability and management of the Asian elephant} 2 (Elephas maximus) population in the Endau Rompin 3 landscape, Peninsular Malaysia

Salman Saaban ${ }^{1}$, Mohd Nawayai Yasak ${ }^{1}$, Melvin Gumal ${ }^{2}$, Aris Oziar², Francis Cheong ${ }^{3}$, Zaleha Shaari $^{4}$, Martin Tyson ${ }^{5}$, Simon Hedges ${ }^{5}$

${ }^{1}$ Department of Wildlife and National Parks (DWNP), Ministry of Water, Land and Natural 10 Resources, Kuala Lumpur, Malaysia

$11{ }^{2}$ Malaysia Program, Wildlife Conservation Society (WCS), Kuching, Sarawak, Malaysia

$12{ }^{3}$ Johor National Parks Corporation (JNPC), Johor, Malaysia

$13 \quad{ }^{4}$ Department of Town and Country Planning (DTCP), Kuala Lumpur, Malaysia

$14{ }^{5}$ Global Conservation Programs, Wildlife Conservation Society (WCS), Bronx, New York, 15 United States of America

Corresponding Author:

18 Simon Hedges

191 Parc Villas, Belle Vue, Newlyn, Cornwall, TR18 5EA, UK

20 Email address: simonhedges@asianarks.org 
23

24

25

26

27

28

29

30

31

32

33

34

35

36

37

38

39

40

41

42

43

44

45

46

47

48

49

50

51

52

53

54

55

56

57

58

59

60

61

62

63

64

65

66

67

68

\section{Abstract}

The need for conservation scientists to produce research of greater relevance to practitioners is now increasingly recognized. This study provides an example of scientists working alongside practitioners and policy makers to address a question of immediate relevance to elephant conservation in Malaysia and using the results to inform wildlife management policy and practice including the National Elephant Conservation Action Plan for Peninsular Malaysia. Since ensuring effective conservation of elephants in the Endau Rompin Landscape (ERL) in Peninsular Malaysia is difficult without data on population parameters we (1) conducted a survey to assess the size of the elephant population, (2) used that information to assess the viability of the population under different management scenarios including translocation of elephants out of the ERL (a technique long used in Malaysia to mitigate human-elephant conflict (HEC)), and (3) assessed a number of options for managing the elephant population and HEC in the future. Our dung-count based survey in the ERL produced an estimate of $135(95 \% \mathrm{CI}=[80,225])$ elephants in the $2500 \mathrm{~km}^{2}$ area. The population is thus of national significance, containing possibly the second largest elephant population in Peninsular Malaysia, and with effective management elephant numbers could probably double. We used the data from our survey plus other sources to conduct a population viability analysis to assess relative extinction risk under different management scenarios. Our results demonstrate that the population cannot sustain even very low levels of removal for translocation or anything other than occasional poaching. We describe, therefore, an alternative approach, informed by this analysis, which focuses on in situ management and non-translocation-based methods for preventing or mitigating HEC. The recommended approach includes an increase in law enforcement to protect the elephants and their habitat, maintenance of habitat connectivity between the ERL and other elephant habitat, and a new focus on adaptive management.

\section{Introduction}

Asian elephants (Elephas maximus) are declining in the wild as a result of habitat loss, fragmentation, and degradation; illegal killing (e.g. for ivory and other products or in retaliation for crop depredations); and in some countries removal of elephants from the wild (Blake \& Hedges 2004; Choudhury et al. 2008; Leimgruber et al. 2003). Peninsular Malaysia still has relatively extensive tracts of tropical forest that are habitat for elephants, tigers (Panthera tigris), and other endangered species but agricultural expansion (including forest monoculture plantations) is probably the most significant threat to these large mammals in Malaysia (Clements et al. 2010). Such expansion is not new: large tracts of lowland dipterocarp forests have been converted to agricultural plantations as a result of both government and private land development schemes since the early twentieth century (Aiken \& Leigh 1985; Khan 1991). The land area under oil palm plantations in particular has increased dramatically at the expense of elephant habitat. For example, from 1990 through 2005, 55-59\% of oil palm expansion in Malaysia originated from the clearance of natural forests (Koh \& Wilcove 2008). By the time of this study, approximately $27 \%$ of Peninsular Malaysia was covered by rubber and oil palm plantations and small-holdings, with approximately the same total area covered by these crops in 2018 (Malaysian Palm Oil Board data for September 2011 and 2018 and Annual Rubber Statistics for 2010 and 2018 from the Malaysian Department of Statistics). The expansion of industrial-scale agriculture and forest plantations resulted in a large increase in human-elephant 
69

70

71

72

73

74

75

76

77

78

79

80

81

82

83

84

85

86

87

88

89

90

91

92

93

94

95

96

97

98

99

100

101

102

103

104

105

106

107

108

109

110

111

112

113

conflict (HEC) not least because oil palm and rubber are frequently eaten or damaged by elephants, resulting in very large financial losses for plantation owners (Ahmad Zafir \& Magintan 2016). Small-scale village agriculture is also vulnerable to crop depredations by elephants. In addition to such HEC, the fragmentation and loss of elephant habitat increases the ease of access for poachers and disrupts elephant movements, ultimately leading to the creation of small isolated populations (Clements et al. 2010).

As the area under rubber, oil palm, and other plantation crops expanded, particularly as a result of major land development initiatives beginning in the 1910s and 1960s, the most frequent approach to dealing with HEC was to kill the elephants. For example, between 1967 and 1977, 120 crop-raiding elephants were killed (Khan 1991). Starting in 1974, however, the Department of Wildlife and National Parks (DWNP) began implementing an alternative strategy known as translocation, which involves the capture and removal of elephants from conflict areas and their subsequent release in a small number of protected areas, especially Taman Negara. Between 1974 and 2005, DWNP translocated 527 elephants (DWNP 2006). Despite the best of intentions, the dense forest and difficult terrain in the release sites generally prevented post-release monitoring and thus an evaluation of the translocation program. However, two elephants (one male, one female) were fitted with satellite telemetry collars and the subsequent monitoring revealed that translocated elephants do not necessarily remain within release sites. For example, the adult female released in Taman Negara left that national park and ranged erratically over an area of almost $7000 \mathrm{~km}^{2}$ (Stüwe et al. 1998). Moreover, in addition to the uncertain outcomes of the translocation program, it is expensive, involves dangers for both people and elephants, and perhaps most significantly, the impact of capturing and removing elephants on the source populations themselves is poorly known.

There is, therefore, a need to consider alternatives to translocation and more generally to better incorporate elephant conservation into national development strategies, especially land use planning, as part of Malaysia's strategy of balancing development and conservation. This need is perhaps most clear in the southern part of the Malaysian peninsula, including in the Endau Rompin Landscape (ERL), where significant changes in land use are currently in progress or at the planning stage with the potential for significant increases in HEC as well as the loss of connectivity between areas of wildlife habitat. The ambitious Central Forest Spine (CFS) plan of the Malaysian Government aims to maintain such connectivity but to be successful needs to be informed by up to date information on the distribution of elephants and other wildlife distribution (DTCP 2009).

The ERL comprises Endau Rompin State Park (in Pahang State), Endau Rompin Johor National Park (Johor State), and large areas of Permanent Reserve Forest in Johor and Pahang States that are connected to the two parks (Fig. 1). The ERL covers an area of about $3600 \mathrm{~km}^{2}$, contains what is believed to be one of the three most important elephant populations in Peninsular Malaysia, and contains a CITES ${ }^{1}$ Monitoring the Illegal Killing of Elephants (MIKE) program site. The ERL is located within a matrix of other land cover types, especially oil palm and rubber plantations to the north, west, and south. The presence of these plantations adjacent to elephant habitat has led to high levels of HEC and significant numbers of elephants have been translocated out of the ERL as a result (DWNP 2006).

\footnotetext{
${ }^{1}$ Convention on International Trade in Endangered Species of Wild Fauna and Flora.
} 
114

115 The objectives of our study were, therefore, to provide up to date information on the elephant

116 population in the ERL (because such data were lacking) and to use those data to help improve

117 the conservation and management of the species. Specifically, we conducted a survey to assess

118 the size of the elephant population (which was unknown), used that information to assess the

119

120

121

122

123

124

125

126

127

128

129

130

131

132

133

134

135

136

137

138

139

140

141

142

143

144

145

146

147

148

149

150

151

152

153

154

155

156

157

158

159 viability of the population (which was believed to be closed geographically) under a number of management scenarios especially those involving translocation, and then assessed a number of options for managing the elephant population and HEC in the future. More generally, the need for conservation scientists to produce research of greater relevance to practitioners is now increasingly recognized (Arlettaz et al. 2010; Cook et al. 2009; Laurance et al. 2012; Meijaard \& Sheil 2007; Meijaard et al. 2014). We aimed therefore to provide a concrete example of scientists working alongside practitioners and policy makers to address a question of immediate relevance to wildlife conservation in Malaysia (i.e. the size and viability of a key elephant population and its vulnerability to offtake including translocation and poaching) and then to use the results to inform wildlife management policy and practice in Malaysia.

\section{Materials \& Methods}

\section{Study area}

We used our knowledge of elephant ecology in conjunction with topographic maps, vegetation cover data, and land use data for the ERL, information from our earlier reconnaissance work in the ERL, data from others working in the area, and DWNP data including HEC data to delimit plausible boundaries for the area occupied by the elephant population in the ERL. Thus, for example, large areas of peat swamp were excluded as was the Lingiu Development Zone (Fig. 1). The resulting study area covered c. $2500 \mathrm{~km}^{2}$ and included Endau Rompin State Park (Pahang State), Endau Rompin Johor National Park (Johor State), the CITES MIKE site (Mersing District, Johor State), and a large area of Permanent Reserve Forest in Johor State not included in either the park or the MIKE site (Fig. 2). The forest in the protected areas comprises mixed dipterocarp forest of the Keruing-Red Meranti (Dipterocarpus shorea) and Kapur (Dryobalanpus) types (Wong et al. 1987). During the 1970s and 1980s, selective logging occurred in portions of the protected areas but logging last occurred in 1989 (Aihara et al. 2016). Although the protected areas are largely intact, the forest cover surrounding them has significantly declined due to intensive agricultural activities, particularly the establishment of oil palm plantations, and this land use change was ongoing at the time of the study (Clements et al. 2010; Foo \& Numata 2019).

\section{Population survey}

Dung count-based surveys were conducted to CITES MIKE program standards (Hedges \& Lawson 2006). From late April to the end of August 2008, we used line transect methods to determine elephant dung-pile density (Buckland et al. 2001; Hedges \& Lawson 2006). The 1.5 $\mathrm{km}$ long transects were arranged in clusters along short baselines, with the clusters located systematically (but with a randomly-selected initial coordinate) across the $2500 \mathrm{~km}^{2}$ study area in order to give good geographical coverage. Each cluster had six transects unless part of it fell outside the study area (Fig. 2). 
160 Estimating elephant density from the dung-pile density requires data on rates of elephant 161 defecation and dung-pile decay. Following Hedges and Lawson (2006), we used a mean

162 defecation rate of 18.07 defecations per 24 hours with standard error 0.0698 ; these data were

163 derived from a study of free-ranging elephants in Indonesia (Hedges et al. 2005). We calculated

164 dung decay rate using the method of Laing et al. (2003), which entailed locating cohorts of fresh

165 dung-piles prior to the line transect survey and then revisiting the marked dung-piles half-way

166 through the overall line transect survey period to establish whether they were still present or had

167 decayed. We used logistic regression in program R (R-Development-Core-Team 2008) to

168 characterize the probability of decay as a function of time and estimated the mean time to decay

169 from this function. We analyzed transect data using the program DISTANCE (Thomas et al.

170 2010).

171

172

173

The work was carried out in ERL with the permission of the Malaysian Government's Department of Wildlife and National Parks (DWNP) and the Johor National Parks Corporation

174

175

176

177

178

179 (JNPC). Permission from an Institutional Animal Care and Use Committee (IACUC) or equivalent animal ethics committee was not necessary as only indirect methods of assessing elephant population status were used (counts of dung-piles along transects).

\section{Population viability analysis}

To assess relative extinction risks for the ERL elephant population under different management scenarios, we used our survey data together with data from other populations of wild Asian

182 elephants in order to conduct a population viability analysis (PVA) (Beissinger \& McCullough 2002; Beissinger \& Westphal 1998; Boyce 1992). We built our models in VORTEX Version 9.99, an individual-based simulation program (Lacy et al. 2005; Miller \& Lacy 2005), which has been used for a number of population viability analyses for Asian elephants (Armbruster et al. 1999; Leimgruber et al. 2008; Tilson et al. 1994).

Tilson et al. (Tilson et al. 1994) summarized expert opinion for their models of wild elephant population viability in Sumatra. Following Leimgruber et al. (2008), we also drew on this source

190 and Sukumar (2003) for our models (Tables $1 \& 2$ ). We calculated the elephant carrying capacity of the ERL based on its area $\left(2500 \mathrm{~km}^{2}\right)$ and Sukumar's (2003) estimate that rainforests can support 0.1 elephants $/ \mathrm{km}^{2}$. No trend in carrying capacity was included in our models in order to avoid exaggerating extinction risk given that our primary concern is to model the impact of translocations and other forms of removal (poaching including snaring and retaliatory killing for crop raiding) over a relatively short period. Poaching is not included as a separate named threat in our models because its effects can be simulated by simply treating the translocation-related removals as deaths due to poaching (the underlying model structure and thus the results being the same). As far as we know, no elephants were killed illegally for this in the ERL population during our study, although a small number have been subsequently been killed illegally. In addition, we adopted the assumption of Tilson et al. (1994) and Sukumar (2003) that male mortality rates for Asian elephants are higher than those of females because of selective poaching for ivory, competition for mates including fights with other males, and the higher metabolic demands resulting from musth and larger body size. The effects of such differential mortality rates are reflected in the female-biased sex ratios seen in wild elephant populations. Inter-calving interval has been reported as 4.5-5 years in southern India but $c .6$ years in 
206

207

208

209

210

211

212

213

214

215

216

217

218

219

220

221

222

223

224

225

226

227

228

229

230

231

232

233

234

235

236

237

238

239

240

241

242

243

244

245

246

247

248

249

250

251

Indonesia (Tilson et al. 1994), so we assumed female reproductive rate was 0.18 offspring/mature female/year but also considered rates of 0.16 offspring/mature female/year and 0.20 offspring/mature female/year to be plausible and incorporated them in our sensitivity analyses. We assumed stochastic variation in environmental conditions equally affected reproduction and mortality and this variation was about $20 \%$ of the mean value (Leimgruber et al. 2008; Tilson et al. 1994). We modeled the ERL population as a single closed population, with no migration to or from other areas in Peninsular Malaysia, based on recent survey and habitat connectivity data (Gumal et al. 2009) as well as the authors' personal observations and local DWNP staff's observations (DWNP pers comm). We kept the basic parameter values shown in Table 2 constant in all models. Each model was run over 100 years with 1-year time steps and 500 iterations.

We considered five levels of elephant removal (permanent translocation out of the ERL), these ranged from no removal to a high rate of six animals per year (Table 3 ). These rates, especially the 'very low' and 'low' rates, are considered realistic based on the history of translocation in the ERL area. The removal scenarios of Table 3 also reflect the typical intention of the DWNP capture teams to translocate family units (DWNP 2006). We modeled scenarios with and without catastrophes, which were defined as floods and disease. Following Tilson et al. (1994), a 4\% probability of drought lowering fertility by $40 \%$ and killing $5 \%$ of individuals, and a $1 \%$ probability of disease killing $10 \%$ of individuals was assumed.

The ERL elephant population was considered extinct if one of the sexes declined to zero but we also included two levels of quasi-extinction, defined as population size declining below 30 and 50 individuals, respectively. To determine the robustness of our baseline models, we conducted a sensitivity analysis. Following Leimgruber et al. (2008), we increased and decreased the most important vital rates (number of offspring per mature female per year and mortality rate) as discussed above and shown in Table 4 and Table S1 in the Supplemental Information.

\section{Results}

\section{Population survey}

\section{Dung decay rate estimation}

A total of 492 fresh dung-piles were found in three large zones (Rompin, Selai, and Peta) spread across the study area, monitored from 27 August 2007 to 30 May 2008, and classified during the second and third weeks of June 2008. Of those 492 dung-piles, 48 were not found again or were destroyed by construction works. The data for the remaining 446 dung-piles were used in the analyses. Logistic regression indicated a mean time to disappear of 308.67 days $(\mathrm{SE}=16.01)$, which is within the expected range for Southeast Asian rain forests (Hedges et al. 2005).

\section{Line transect-based survey}

During the 4-month (late April-late August 2008) line transect-based survey, we found 226 elephant dung-piles along line transects totaling $194.56 \mathrm{~km}$ in length. Applying a mean defecation rate of $18.07(\mathrm{SE}=0.0698)$ dung-piles per 24-hours and the decay rate given above, 
252

253

254

255

256

257

258

259

260

261

262

263

264

265

266

267

268

269

270

271

272

273

274

275

276

277

278

279

280

281

282

283

284

285

286

287

288

289

290

291

292

293

294

295

296

297

we estimated population density as $0.0538(95 \% \mathrm{CI}=[0.0322,0.0901])$ elephants $/ \mathrm{km}^{2}$ and population size as $135(95 \% \mathrm{CI}=[80,225])$ elephants in the $2500 \mathrm{~km}^{2}$ study area.

\section{Population viability analysis}

A total of 234 scenarios were analyzed (Tables 5-7; Figs. 3-8; Table S1 in Supplemental Information). The results suggest that the ERL elephant population could be self-sustaining provided no animals are removed for translocation or killed (and the basic assumptions of the PVA model are met). Our baseline scenarios gave a growth rate of $r=0.006$ in the absence of catastrophes (flood and disease) and $r=0.004$ when we included catastrophes in the models. All baseline scenarios returned a $0 \%$ probability of extinction in the absence of removals (Table 5; Fig. 3). Reducing the natality rate from 0.18 to 0.16 offspring/mature female/year, a rate also considered to be realistic based on data from Indonesia, results in growth rates of $r=0$ and 0.003 with and without catastrophes, respectively, but still returns a $0 \%$ probability of extinction in the absence of removals (Table 6; Fig. 4). Under the most optimistic scenarios (natality rate of 0.20 offspring/mature female/year, mortality rates reduced by $20 \%$ ), the ERL population has a $0 \%$ probability of extinction and grows at a rate of $r=0.013$ and 0.015 with and without catastrophes, respectively (Table 7; Fig. 5).

Including elephant removals in the models results in very high probabilities of extinction in all scenarios considered realistic. Those scenarios with very low removal rates ( 3 animals removed, every other year; Table 3) and no catastrophes have probabilities of extinction of $63.8-85.2 \%$ over a 100-year period, with mean times to extinction of 81.2-85.4 years (i.e. $<3$ elephant generations), while those scenarios with low removal rates ( 3 animals removed every year) have a $100 \%$ probability of extinction and a mean time to extinction of 44.4-46.5 years in the absence of catastrophes (Tables $5 \& 6$ ). Even the most optimistic scenarios return a $100 \%$ probability of extinction and a mean time to extinction of 52.6 years when low removal rates - but no catastrophes - are included in the models (Table 7). On the other hand, a high rate of capture (6 animals removed every year) is predicted to lead to the extinction of the ERL elephant population in c. 27-29 years if catastrophes are included in the models (mean time to extinction 27.4-27.9 years; Tables 5-7; Figs. 3-5).

All our models were robust, with changes in natality and mortality rates of up to $20 \%$ causing only minor changes in growth rates, probability of extinction, or mean time to extinction, and thus had no qualitative effects on our conclusions. Most notably, all the sensitivity analysis scenarios with the low capture rate ( 3 animals removed every year) resulted in a 100\% probability of extinction regardless of other parameter values (Figs. 6-8; Supporting information).

\section{Discussion}

\section{The need for science-based conservation management}

Species conservation is more effective when it is based on good science and reliable evidence but too often this is not the case (Hayward et al. 2015; Pullin \& Knight 2001; Sutherland et al. 2004). While there is a growing appreciation of the dangers of making interventions without a 
298

299

300

301

302

303

304

305

306

307

308

309

310

311

312

313

314

315

316

317

318

319

320

321

322

323

324

325

326

327

328

329

330

331

332

333

334

335

336

337

338

339

340

341

342

343

proper understanding of their impact or effectiveness, this appreciation is growing too slowly and is failing to have sufficient impact on conservation practice, even for high profile species such as elephants (Elephas maximus, Loxodonta africana) and tigers (Panthera tigris) (Blake \& Hedges 2004; Hedges \& Gunaryadi 2009; Karanth et al. 2003; Young \& Van Aarde 2011). Moreover, there is an increasingly recognized need for conservation scientists to produce research of greater relevance to conservation practitioners (Laurance et al. 2012), and to bridge the gap between research and publication on the one hand and implementation on the other (Arlettaz et al. 2010; Meijaard \& Sheil 2007; Meijaard et al. 2014). This study provides an example of conservation scientists working alongside practitioners and policy makers to address a question of immediate relevance to the conservation of wildlife, in this case how best to protect an important population of elephants, jointly publishing the results and - critically - using them to inform wildlife management policy and practice in Malaysia including the recent (2013) National Elephant Conservation Action Plan (NECAP) for Peninsular Malaysia (DWNP 2013). Specifically, scientists from the Wildlife Conservation Society (WCS, an international NGO with a national program in Malaysia) worked alongside practitioners and policy makers from the Department of Wildlife and National Parks (DWNP) and the Johor National Parks Corporation (JNPC) to assess the size and viability of the ERL elephant population. The results of the study were then used by staff from DWNP, JNPC, and WCS to help prepare the National Elephant Conservation Action Plan for Peninsular Malaysia, which was published in 2013, after a series of workshops convened by DWNP and WCS over 2011-2013 and featuring inputs from the Department of Town and Country Planning (DTCP), NGOs, universities, and other representatives of civil society. In addition, staff from DWNP, JNPC, and WCS are all authors of this paper.

\section{Significance of Endau Rompin's elephant population}

The ERL elephant population estimate, $135(95 \% \mathrm{CI}=[80,225])$ elephants, is only the second such estimate for Peninsular Malaysia to be based on modern sampling-based methods (Clements et al. 2010), the first being the 2007 population estimate of $631(95 \% \mathrm{CI}=[436,915])$ elephants in Taman Negara, which also resulted from a DWNP/WCS project (Hedges et al. $2008)$. The estimated population density of $0.0538(95 \% \mathrm{CI}=[0.0322,0.0901])$ elephants $/ \mathrm{km}^{2}$ in the ERL is somewhat lower than the 0.1 elephants $/ \mathrm{km}^{2}$ that Sukumar (2003) suggests Asian rainforests can support (although note the upper confidence limit) and considerably lower than the 0.57 elephants $/ \mathrm{km}^{2}$ reported by Hedges et al. (2005) for a rainforest area in nearby Sumatra. These lower densities may reflect differences in habitat quality but are perhaps more likely to be an indication of the effect of previous translocations of elephants out of the ERL as well as possible losses to poachers or retaliatory killing for HEC. Nevertheless, our results suggest that the elephant population in the ERL is of clear national importance and indeed regional importance given $(1)$ the preponderance of small $(<500)$ elephant populations in highly fragmented habitat in Southeast Asia (Hedges et al. 2009; Leimgruber et al. 2003); (2) that, with effective protection, the population could at least double in size to the estimated carrying capacity of approximately 250 elephants (a doubling in elephant numbers would take $c$. 23-35 years if population annual growth rates could be increased to $2-3 \%$ ); and (3) there is still an opportunity for gene flow to be re-established with other elephant populations within the Central Forest Spine (CFS) to the north since the Master Plan for the CFS envisages $51,000 \mathrm{~km}^{2}$ of contiguous forests, with protected core areas, including those in the ERL, linked within the greater landscape by ecological corridors (Brodie et al. 2016; DTCP 2009). However, the

Peer] reviewing PDF | (2019:05:37435:1:1:NEW 8 Nov 2019) 
344 challenges of re-establishing connectivity for elephants should not be underestimated given the

345

346

347

348

349

350

351

352

353

354

355

356

357

358

359

360

361

362

363

364

365

366

367

368

369

370

371

372

373

374

375

376

377

378

379

380

381

382

383

384

385

386

387

388

389 risk of further deforestation, the shortage of resources to implement the CFS, and governance conflicts between Federal and State governments (Maniam \& Singaravelloo 2015).

\section{Population viability analysis and the effects of translocations}

Population viability modeling is sometimes controversial because the requisite data are often lacking. In order to minimize such difficulties, we followed the recommendations of Beissinger and Westphal (1998) and Burgman and Possingham (2000) in treating our results as relative, rather than absolute, estimates of extinction risk under different management scenarios, with projections over a short time period (100-years). Linkie et al. (2006) also used this approach for a conceptually similar analysis of tiger population viability in the Kerinci Seblat region of Sumatra. Thus the conclusion of Armbruster et al. (1999), that examining population persistence over a 100-year time frame seriously underestimates the absolute risk of population extinction for species with long generation times (such as elephants) over a 1000-year period, is not pertinent to this analysis.

The results of even our most optimistic scenarios are alarming, since relative extinction risks are very high even when rates of elephant removal are very low or low, with local extinction likely to occur in less than three elephant generations. Moreover, the results of other scenarios judged to be realistic suggest that local extinction is likely to occur within 1-2 elephant generations. Thus, the ERL population appears not to be able to sustain any level of removal for translocation or indeed anything other than occasional poaching. Furthermore, if we consider the quasiextinction scenarios (reduction to $<30$ or $<50$ individuals), which of course result in much more rapid crossing of quasi-extinction thresholds, it is clear that the ERL elephant population is likely to lose much of its social integrity and cease playing a significant ecological role in a relatively short time (potentially $<15$ years; baseline scenario with high removal and quasi-extinction at 50 individuals) unless a no-translocation management policy is implemented.

\section{Management implications}

\section{Moving away from translocation of elephants for managing human-elephant conflict (HEC) in the National Elephant Conservation Action Plan (NECAP)}

Our results suggest that Malaysia has to move away from translocation as a major method for managing HEC in Peninsular Malaysia, except in the case of 'doomed' individuals or herds (e.g. very small numbers of elephants that are isolated from other elephant populations and which may also have a highly-skewed sex- or age-structure and/or are in areas of habitat scheduled for complete conversion to other land uses). Translocation of such doomed individuals or herds to protected areas will in some cases be the only appropriate management strategy, and is the strategy recommended in the National Elephant Conservation Action Plan (NECAP), which DWNP prepared with the Wildlife Conservation Society - Malaysia Program and other partners, and which was launched officially in November 2013. More generally, the NECAP calls for elephant conservation in Peninsular Malaysia to be governed by the following principles: (1) promotion of human-elephant coexistence; (2) restoration and maintenance of socially and ecologically functional elephant population densities; (3) an emphasis on maintaining the 
390 species' present geographical range; (4) management of the CFS as three Managed Elephant

391 Ranges (MERs); and (5) an emphasis on monitoring and adaptive management to help ensure the

392 plan is implemented successfully. The MER concept provides a landscape-level approach in

393 which planners assess the habitat requirements of elephants over large areas and allow for

394 compatible human activities such as reduced impact forestry, slow rotation shifting cultivation,

395

396

397

398

399

400

401

402

403

404

405

406

407

408

409

410

411

412

413

414

415

416

417

418

419

420

421

422

423

424

425

426

427

428

429

430

431

432

433

434

435 and controlled livestock grazing in some zones. MERs are typically established outside of usually as extensions to - existing protected areas, and as such often include habitat corridors linking protected areas. The MER concept is particularly attractive, and probably has the greatest potential, where protected areas consist primarily of steep hilly terrain or are small and the surrounding areas are disproportionately important to elephant populations but contain agriculture or villages (McNeely \& Sinha 1981; Olivier 1978; Santiapillai \& Jackson 1990).

\section{Non-translocation-based approaches to managing HEC and the need for research on elephant movements}

For the ERL, the new NECAP approach includes explicit recognition that the area's elephant population cannot sustain even very low levels of translocation, as we demonstrate in this paper, and so other means of preventing HEC or mitigating its effects will be needed. For large commercial plantations, a non-translocation approach to managing HEC is likely to require the use of physical barriers such as fences. Thus, it will be necessary to construct (or improve existing) barriers, especially high-voltage, well-designed, and above-all well-maintained electric fences. Use of electric fences around privately-owned cultivated lands has achieved notable successes compared to government-owned electric fences in India (Nath \& Sukumar 1998), while a success rate of $80 \%$ has been reported for electric fences around oil palm and rubber plantations in Malaysia (Sukumar 2003). Nevertheless, the use of fencing for wildlife management has attracted considerable controversy in recent years (Creel et al. 2013; Packer et al. 2013; Pfeifer et al. 2014; Woodroffe et al. 2014a; Woodroffe et al. 2014b), in part because of the inherent risks of population fragmentation. Thus, if more widespread use of effective barriers to elephant movement is not itself to pose a threat to the elephant population by, for example, trapping elephant groups in areas too small to support them, it will be necessary to position the barriers taking elephant habitat requirements and ranging behavior into account. This will entail using data on elephant movements collected using satellite telemetry (i.e. GPS collars) and fortunately a large dataset on elephant movements in Peninsular Malaysia is now available (Ahimsa Campos-Arceiz pers. comm.).

The telemetry-based data on elephant ecology and behavior will also greatly assist with the Malaysian Government's plans to maintain elephant habitat connectivity throughout the CFS, and ultimately to re-establish gene flow between the major elephant populations within the CFS, since the study will allow critical areas for elephants to be identified and thus facilitate "elephantfriendly' land use planning.

In addition, the needs of villagers must not be forgotten, as their small plantations and other agricultural areas are also affected by HEC. Prevention and mitigation of HEC at this scale will require a combination of community-based crop guarding methods such as simple alarm systems and village crop defense teams (Fernando et al. 2008; Osborn \& Parker 2002), the application of which has resulted in notable successes in parts of Asia (Davies et al. 2011; Gunaryadi et al. 
436

437

438

439

440

441

442

443

444

445

446

447

448

449

450

451

452

453

454

455

456

457

458

459

460

461

462

463

464

465

466

467

468

469

470

471

472

473

474

475

476

477

478

479

480

2017; Hedges \& Gunaryadi 2009) and possibly also electric fencing around particularly vulnerable areas (rather than fencing the entire elephant habitat-agriculture interface). Again, it will be necessary to position any barriers to elephant movements taking elephant habitat requirements and ranging behavior into account, something that is often insufficiently recognized as being necessary.

\section{The need for law enforcement efforts to be increased}

Finally, while our PVA results show that the ERL elephant population cannot sustain even low levels of removal for translocation they also show that it is equally vulnerable to even low levels of poaching. This can be seen by simply treating the translocation-related removals we modeled as deaths due to poaching because, as already noted, the underlying model structure and thus the results are the same. Moreover, even in the scenarios (including those in the sensitivity analyses) which included no translocation-related removals, population growth rates were still very low or, in some cases, negative, suggesting that management aimed at reducing elephant mortality rates is needed. Clearly, then, law enforcement efforts including anti-poaching patrols will be needed in order to protect both the ERL elephants from illegal killing (including retaliatory killing resulting from HEC, accidental deaths due to snaring, and poaching for ivory) and their habitat from encroachment and other threats. All law enforcement work and reporting thereof should be to internationally-agreed standards (Appleton et al. 2003; Stokes 2012).

\section{Conclusions}

The Endau Rompin Landscape (ERL) elephant population is of clear national and regional significance, and with effective management elephant numbers could double. It is however currently of a size that makes it highly vulnerable to even low levels of illegal killing or removal for translocation. Management of the population in the future should therefore focus on (1) nontranslocation-based methods for preventing or mitigating HEC including well-maintained electric fences and other deterrents to elephant incursions positioned using data on the elephants' ecology and ranging behavior; (2) effective law enforcement to protect the elephants and their habitat; and (3) efforts to maintain elephant habitat connectivity between the ERL and other elephant habitat within the Central Forest Spine.

\section{Acknowledgements}

We thank Mike Meredith for assistance with the dung survey analyses (by helping to provide training to country program field staff in statistical methods) and Peter Clyne, Ahimsa CamposArceiz, and three anonymous reviewers for helpful comments on an earlier version of this paper. We are grateful to the DWNP's Elephant Unit for sharing their knowledge of translocations and HEC and WCS-Malaysia Program's Elephant and Tiger Projects' field staff for helping with surveys. Finally, we acknowledge the support of the Dato Sri Douglas Uggah for promoting in situ conservation of elephants in Malaysia.

\section{References}


481

482

483

484

485

486

487

488

489

490

491

492

493

494

495

496

497

498

499

500

501

502

503

504

505

506

507

508

509

510

511

512

513

514

515

516

517

518

519

520

521

522

523

524

525

526

527

528

529

Ahmad Zafir AW, and Magintan D. 2016. Historical review of human-elephant conflict in Peninsular Malaysia. Journal of Wildlife and Parks 31:1-19.

Aihara Y, Hosaka T, Yasuda M, Hashim M, and Numata S. 2016. Mammalian wildlife tourism in Southeast Asian tropical rainforests: the case of Endau Rompin National Park, Malaysia. Journal of Tropical Forest Science:167-181.

Aiken SR, and Leigh CH. 1985. On the declining fauna of Peninsular Malaysia in the post-colonial period. Ambio 14:15-22.

Appleton MR, Texon GI, and Uriarte MT. 2003. Competence Standards for Protected Area Jobs in South East Asia: ASEAN Regional Centre for Biodiversity Conservation, Los Baños, Philippines.

Arlettaz R, Schaub M, Fournier J, Reichlin TS, Sierro A, Watson JEM, and Braunisch V. 2010. From Publications to Public Actions: When Conservation Biologists Bridge the Gap between Research and Implementation. Bioscience 60:835-842. 10.1525/bio.2010.60.10.10

Armbruster P, Fernando P, and Lande R. 1999. Time frames for population viability analysis of species with long generations: an example with Asian elephants. Animal Conservation 2:69-73. 10.1111/j.1469-1795.1999.tb00050.x

Beissinger SR, and McCullough DR. 2002. Population Viability Analysis. University of Chicago Press, Chicago, USA and London, UK.

Beissinger SR, and Westphal M. 1998. On the use of demographic models of population viability in endangered species management. Journal of Wildlife Management 62:821-841.

Blake S, and Hedges S. 2004. Sinking the flagship: The case of forest elephants in Asia and Africa. Conservation Biology 18:1191-1202.

Boyce MS. 1992. Population viability analysis. Annual Review of Ecology and Systematics 23:481-506.

Brodie JF, Paxton M, Nagulendran K, Balamurugan G, Clements GR, Reynolds G, Jain A, and Hon J. 2016. Connecting science, policy, and implementation for landscape-scale habitat connectivity. Conservation Biology 30:950-961. 10.1111/cobi.12667

Buckland ST, Andersen DR, Burnham KP, Laake JL, Borchers DL, and Thomas L. 2001. Introduction to Distance Sampling: Estimating Abundance of Biological Populations. New York, USA: Oxford University Press Inc.

Burgman M, and Possingham HP. 2000. Population viability analysis for conservation: the good, the bad and the undescribed. In: A.G. Y, and Clarke GM, eds. Genetics, Demography and Viability of Fragmented Populations: Cambridge University Press, London, UK, 97-112.

Choudhury A, Lahiri Choudhury DK, Desai A, Duckworth JW, Easa PS, Johnsingh AJT, Fernando P, Hedges S, Gunawardena M, Kurt F, Karanth KU, Lister A, Menon V, Riddle H, Rübel A, and Wikramanayake E. 2008. Elephas maximus. In: IUCN 2011. IUCN Red List of Threatened Species. Version 2011.2. www.iucnredlist.org. Downloaded on 03 December 2011.

Clements R, Rayan D, Ahmad Zafir A, Venkataraman A, Alfred R, Payne J, Ambu L, and Sharma D. 2010. Trio under threat: can we secure the future of rhinos, elephants and tigers in Malaysia? Biodiversity and Conservation 19:1115-1136. 10.1007/s10531-009-9775-3

Cook CN, Hockings M, and Carter RW. 2009. Conservation in the dark? The information used to support management decisions. Frontiers in Ecology and the Environment 8:181-186. 10.1890/090020

Creel S, Becker MS, Durant SM, M'Soka J, Matandiko W, Dickman AJ, Christianson D, Dröge E, Mweetwa T, Pettorelli N, Rosenblatt E, Schuette P, Woodroffe R, Bashir S, Beudels-Jamar RC, Blake S, Borner M, Breitenmoser C, Broekhuis F, Cozzi G, Davenport TRB, Deutsch J, Dollar L, Dolrenry S, Douglas-Hamilton I, Fitzherbert E, Foley C, Hazzah L, Henschel P, Hilborn R, Hopcraft JGC, Ikanda D, Jacobson A, Joubert B, Joubert D, Kelly MS, Lichtenfeld L, Mace GM, Milanzi J, Mitchell N, Msuha M, Muir R, Nyahongo J, Pimm S, Purchase G, Schenck C, SilleroZubiri C, Sinclair ARE, Songorwa AN, Stanley-Price M, Tehou CA, Trout C, Wall J, Wittemyer G, and Zimmermann A. 2013. Conserving large populations of lions - the argument for fences has holes. Ecology Letters 16:1413-e1413. 10.1111/ele.12145

Peer) reviewing PDF | (2019:05:37435:1:1:NEW 8 Nov 2019) 
530

531

532

533

534

535

536

537

538

539

540

541

542

543

544

545

546

547

548

549

550

551

552

553

554

555

556

557

558

559

560

561

562

563

564

565

566

567

568

569

570

571

572

573

574

575

576

577

578

579

580

Davies TE, Wilson S, Hazarika N, Chakrabarty J, Das D, Hodgson DJ, and Zimmermann A. 2011. Effectiveness of intervention methods against crop-raiding elephants. Conservation Letters 4:346354. 10.1111/j.1755-263X.2011.00182.x

DTCP. 2009. Central Forest Spine (CFS): Masterplan for Ecological Linkages: Department of Town and Country Planning (DTCP), Malaysia.

DWNP. 2006. Pelan Pengurusan Gajah Semenanjung Malaysia Department of Wildlife and National Parks (DWNP), Kuala Lumpur, Malaysia.

DWNP. 2013. National Elephant Conservation Action Plan: Blueprint to Save Malaysian Elephants: Department of Wildlife and National Parks (DWNP) Peninsular Malaysia, Kuala Lumpur, Malaysia.

Fernando P, Kumar MA, Williams AC, Wikramanayake E, Aziz T, and Singh SM. 2008. Review of Human-Elephant Conflict Mitigation Measures Practiced in South Asia. AREAS Technical Support Document: WWF - World Wide Fund for Nature, Switzerland.

Foo YS, and Numata S. 2019. Deforestation and forest fragmentation in and around Endau-Rompin National Park, Peninsular Malaysia. Tropics 28:23-37.

Gumal M, Oziar A, Wong EP, Chin C, Ng S, and Hedges S. 2009. WCS/GoM Peninsular Malaysia Elephant Project, Year 2: Asian Elephant surveys and Capacity-building in Endau Rompin National Park, Peninsular Malaysia. Final Report to the U.S. Fish \& Wildlife Service, March 2009. Bronx, NY, USA: Wildlife Conservation Society.

Gunaryadi D, Sugiyo, and Hedges S. 2017. Community-based human-elephant conflict mitigation: The value of an evidence-based approach in promoting the uptake of effective methods. PLOS ONE 12:e0173742. 10.1371/journal.pone.0173742

Hayward MW, Boitani L, Burrows ND, Funston PJ, Karanth KU, MacKenzie DI, Pollock KH, and Yarnell RW. 2015. Ecologists need robust survey designs, sampling and analytical methods. Journal of Applied Ecology 52:286-290. 10.1111/1365-2664.12408

Hedges S, Fisher K, and Rose R. 2009. Range-wide Priority Setting Workshop for Asian Elephants (Elephas maximus). Final Report: December 2009. A report to the U.S. Fish \& Wildlife Service. Bronx, NY, USA: Wildlife Conservation Society.

Hedges S, Gumal M, and Ng S. 2008. WCS/GoM West Malaysian Elephant Project: Year 1, Elephant surveys and training in Taman Negara National Park, Malaysia: Final Report to the U.S. Fish and Wildlife Service, December 2008. Bronx, NY, USA: Wildlife Conservation Society.

Hedges S, and Gunaryadi D. 2009. Reducing human-elephant conflict: do chillies help deter elephants from entering crop fields? Oryx 44:139-146. 10.1017/s0030605309990093

Hedges S, and Lawson D. 2006. Dung Survey Standards for the MIKE Programme: CITES MIKE Programme, Central Coordinating Unit, PO Box 68200, Nairobi, Kenya

Hedges S, Tyson MJ, Sitompul AF, Kinnaird MF, Gunaryadi D, and Aslan. 2005. Distribution, status, and conservation needs of Asian elephants (Elephas maximus) in Lampung Province, Sumatra, Indonesia. Biological Conservation 124:35-48. 10.1016/j.biocon.2005.01.004

Karanth KU, Nichols JD, Seidensticker J, Dinerstein E, Smith JLD, McDougal C, Johnsingh AJT, Chundawat RS, and Thapar V. 2003. Science deficiency in conservation practice: the monitoring of tiger populations in India. Animal Conservation 6:141-146.

Khan M. 1991. The Malayan elephant - a species plan for its conservation: Department of Wildlife and National Parks, Kuala Lumpur, Malaysia.

Koh LP, and Wilcove DS. 2008. Is oil palm agriculture really destroying tropical biodiversity? Conservation Letters 1:60-64. 10.1111/j.1755-263X.2008.00011.x

Lacy RC, Borbat M, and Pollak JP. 2005. VORTEX: A Stochastic Simulation of the Extinction Process.Version 9.50: Chicago Zoological Society, Brookfield, Illinois, USA.

Laing SE, Buckland ST, Burn RW, Lambie D, and Amphlett A. 2003. Dung and nest surveys: estimating decay rates. Journal of Applied Ecology 40:1102-1111.

Laurance WF, Koster H, Grooten M, Anderson AB, Zuidema PA, Zwick S, Zagt RJ, Lynam AJ, Linkie M, and Anten NPR. 2012. Making conservation research more relevant for conservation

Peer] reviewing PDF | (2019:05:37435:1:1:NEW 8 Nov 2019) 
581

582

583

584

585

586

587

588

589

590

591

592

593

594

595

596

597

598

599

600

601

602

603

604

605

606

607

608

609

610

611

612

613

614

615

616

617

618

619

620

621

622

623

624

625

626

627

628

629

630

631

practitioners. Biological Conservation 153:164-168.

http://dx.doi.org/10.1016/j.biocon.2012.05.012

Leimgruber P, Gagnon JB, Wemmer C, Kelly DS, Songer MA, and Selig ER. 2003. Fragmentation of Asia's remaining wildlands: implications for Asian elephant conservation. Animal Conservation 6:347-359.

Leimgruber P, Senior B, Aung M, Songer MA, Mueller T, Wemmer C, and Ballou JD. 2008. Modeling population viability of captive elephants in Myanmar (Burma): implications for wild populations. Animal Conservation 11:198-205.

Linkie M, Chapron G, Martyr DJ, Holden J, and Leader-Williams N. 2006. Assessing the viability of tiger subpopulations in a fragmented landscape. Journal of Applied Ecology 43:576-586. $10.1111 /$ j.1365-2664.2006.01153.x

Maniam A, and Singaravelloo K. 2015. Impediments to linking forest islands to Central Forest Spine in Johor, Malaysia. International Journal of Social Science and Humanity 5:22.

McNeely JA, and Sinha MK. 1981. Protected areas for Asian elephants. Parks 6:4-7.

Meijaard E, and Sheil D. 2007. Is wildlife research useful for wildlife conservation in the tropics? A review for Borneo with global implications. Biodiversity and Conservation 16:3053-3065. 10.1007/s10531-007-9161-y

Meijaard E, Sheil D, and Cardillo M. 2014. Conservation: Focus on implementation. Nature 516:37-37. $10.1038 / 516037 \mathrm{~d}$

Miller PS, and Lacy RC. 2005. VORTEX: A Stochastic Simulation of the Extinction Process. Version 9.50 User's Manual: IUCN/SSC Conservation Breeding Specialist Group, Apple Valley, Minnesota, USA.

Nath C, and Sukumar R. 1998. Elephant-human conflict in Kodagu, southern India: distribution patterns, people's perceptions and mitigation methods: Asian Elephant Conservation Centre, Bangalore, India.

Olivier RCD. 1978. Conservation of the Asian Elephant. Environmental Conservation 5:146. doi:10.1017/S0376892900005646

Osborn FV, and Parker GE. 2002. Living with elephants II: a manual: Mid Zambezi Elephant Project, Harare, Zimbabwe.

Packer C, Swanson A, Canney S, Loveridge A, Garnett S, Pfeifer M, Burton AC, Bauer H, and MacNulty D. 2013. The case for fencing remains intact. Ecology Letters 16:1414, e1414. 10.1111/ele.12171

Pfeifer M, Packer C, Burton AC, Garnett ST, Loveridge AJ, MacNulty D, and Platts PJ. 2014. In defense of fences. Science 345:389.

Pullin AS, and Knight TM. 2001. Effectiveness in conservation practice: pointers from medicine and public health. Conservation Biology 15:50-54.

R-Development-Core-Team. 2008. $R$ : A language and environment for statistical computing: $\mathrm{R}$ Foundation for Statistical Computing, Vienna, Austria.

Santiapillai C, and Jackson P. 1990. The Asian Elephant: An Action Plan for its Conservation: IUCN/SSC Asian Elephant Specialist Group, Gland, Switzerland.

Stokes EJ. 2012. Assessing threats and monitoring law enforcement. In: Hedges S, ed. Monitoring elephants and assessing threats: a manual for researchers, managers and conservationists: Universities Press (India) Private Limited, Himayatnagar, India, 259-292.

Stüwe M, Abdul JB, Nor BM, and Wemmer CM. 1998. Tracking the movements of translocated elephants in Malaysia using satellite telemetry. Oryx 32:68-74.

Sukumar R. 2003. The living elephants: evolutionary ecology, behavior, and conservation. Oxford, UK: Oxford University Press.

Sutherland WJ, Pullin AS, Dolman PM, and Knight TM. 2004. The need for evidence-based conservation. Trends in Ecology \& Evolution 19:305-308.

Thomas L, Buckland ST, Rexstad EA, Laake JL, Strindberg S, Hedley SL, Bishop JRB, Marques TA, and Burnham KP. 2010. Distance software: design and analysis of distance sampling surveys for estimating population size. Journal of Applied Ecology 47:5-14.

Peer] reviewing PDF | (2019:05:37435:1:1:NEW 8 Nov 2019) 
632 Tilson R, Soemarna K, Ramono W, Sukumar R, Seal U, Traylor-Holzer K, and Santiapillai C. 1994.

633

634

635

636

637

638

639

640

641

642

643

644

645

646

647

648

649

650
Asian elephant in Sumatra: population and habitat viability analysis report: IUCN/SSC Captive

Breeding Specialist Group, Bandar Lampung, Indonesia (http://www.cbsg.org/sites/cbsg.org/files/documents/Asian_Elephant_1993.pdf).

Wong K, Saw L, and Kochummen K. 1987. A survey of the forests of the Endau-Rompin area, Peninsular Malaysia: principal forest types and floristic notes. Malayan Nature Journal 41:125-144.

Woodroffe R, Hedges S, and Durant S. 2014a. In defense of fences - Response. Science 345:389-390.

Woodroffe R, Hedges S, and Durant SM. 2014b. To Fence or Not to Fence. Science 344:46-48. $10.1126 /$ science. 1246251

Young KD, and Van Aarde RJ. 2011. Science and elephant management decisions in South Africa. Biological Conservation 144:876-885. 10.1016/j.biocon.2010.11.023

\section{Supplemental Information}

The following material is available for this article online:

Supplemental Table S1. Results of sensitivity analyses for the ERL elephant population viability models. 


\section{Figure 1}

Figure 1. Map of Peninsular Malaysia showing the location of the Endau Rompin Landscape (ERL).

The ERL comprises the areas identified as "Pahang Endau Rompin Landscape" plus the "JWCP site with Lingui area" and the "Lingui area"; the total area of the ERL is c. $3600 \mathrm{~km}^{2}$ and it is entirely within Pahang and Johor States. 


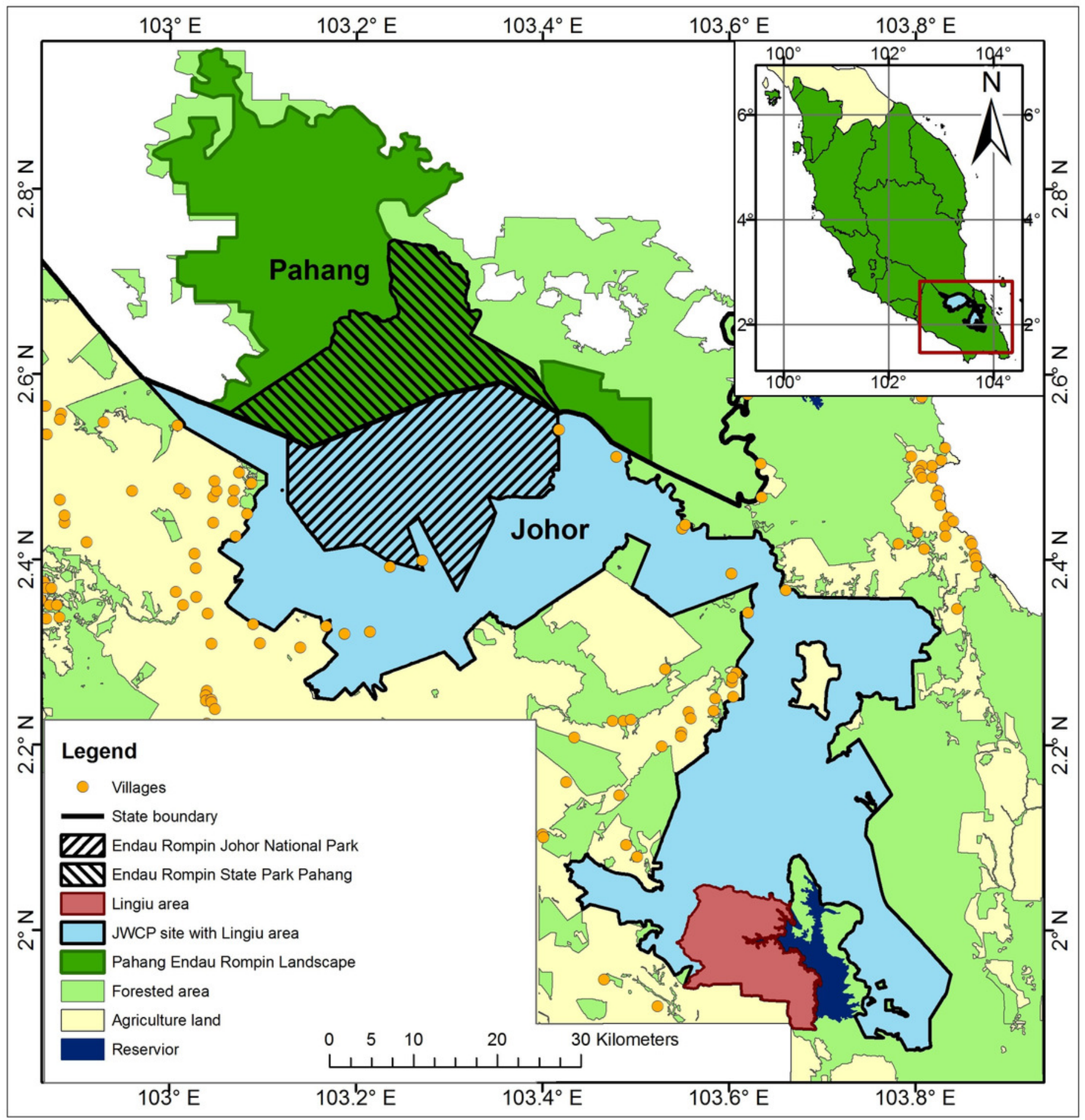


Figure 2

Figure 2. Location of the line transects used for the 2008 survey of the $2500 \mathrm{~km}^{2}$ elephant study area in the Endau Rompin Landscape.

Transects are shown as horizontal black lines; the numbers within the orange circles indicate the number of dung piles found per transect.

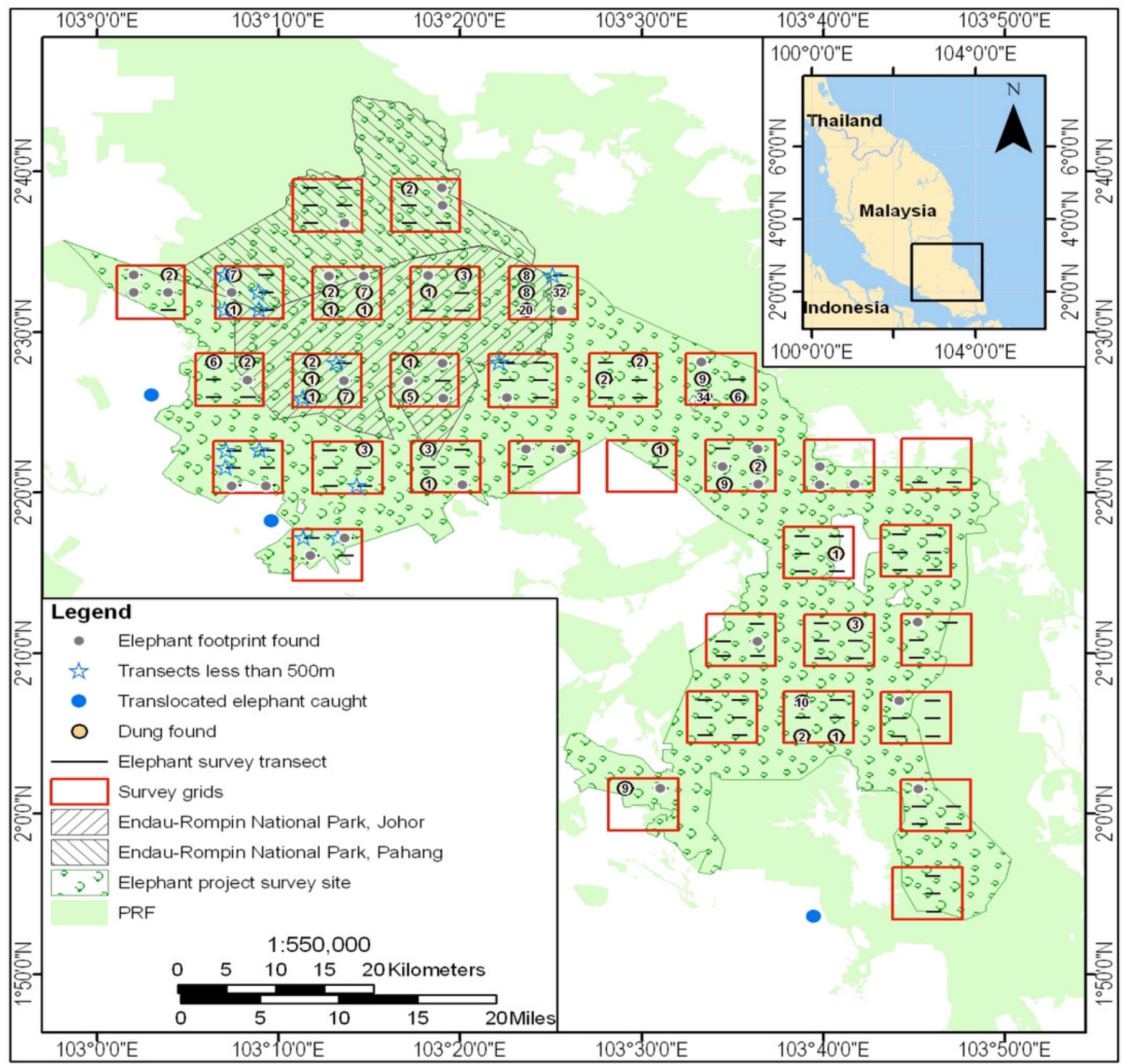


Figure 3

Figure 3. Results of the population viability analysis for all baseline scenarios showing the effect of different elephant removal rates on the probability of extinction (and quasiextinction at 30 and 50 animals, depicted as Q30 and Q50) with and without

For values see Table 4 and for terms used see Table 1. 


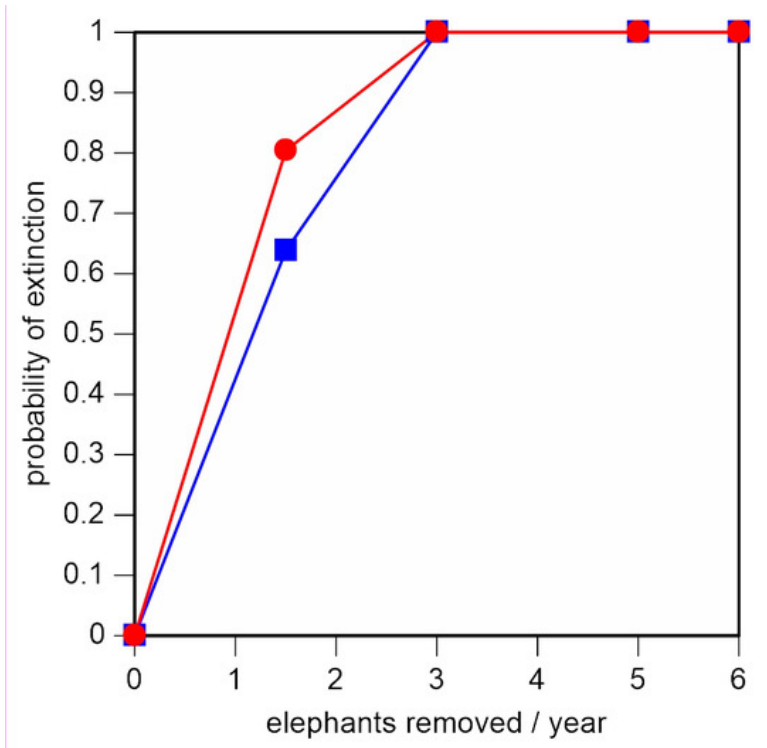

$\rightarrow$ NoQ OC

$\longrightarrow \quad \mathrm{NoQ} 2 \mathrm{C}$
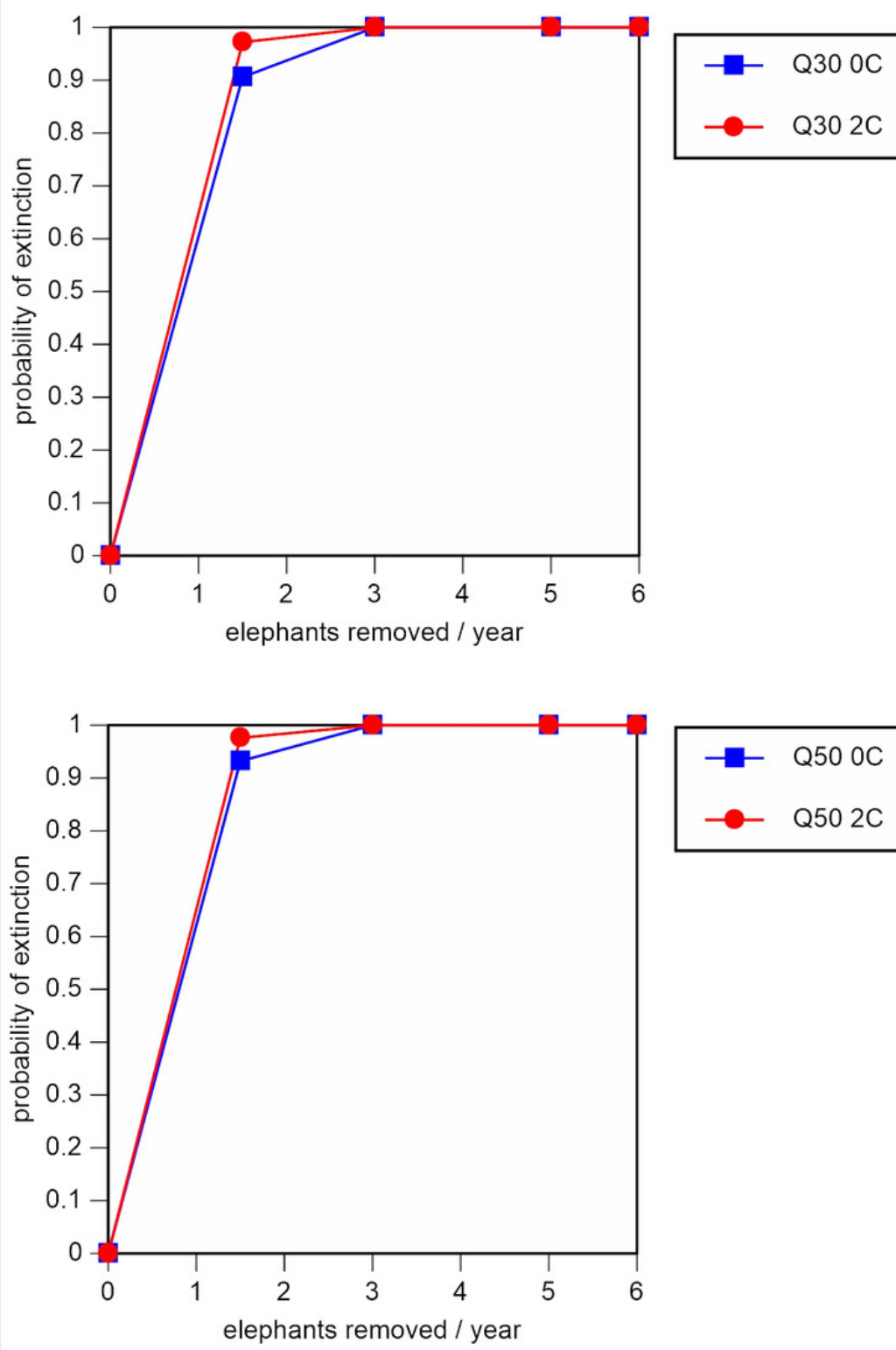

$\rightarrow$ Q50 OC

$\longrightarrow$ Q50 2C 
Figure 4

Figure 4. Results of the population viability analysis for all reduced female breeding rate scenarios (natality rate of 0.16 offspring/mature female/year, all other parameter values the same as in the baseline scenarios) showing the effect of different el

For values see Table 5 and for terms used see Table 1. 


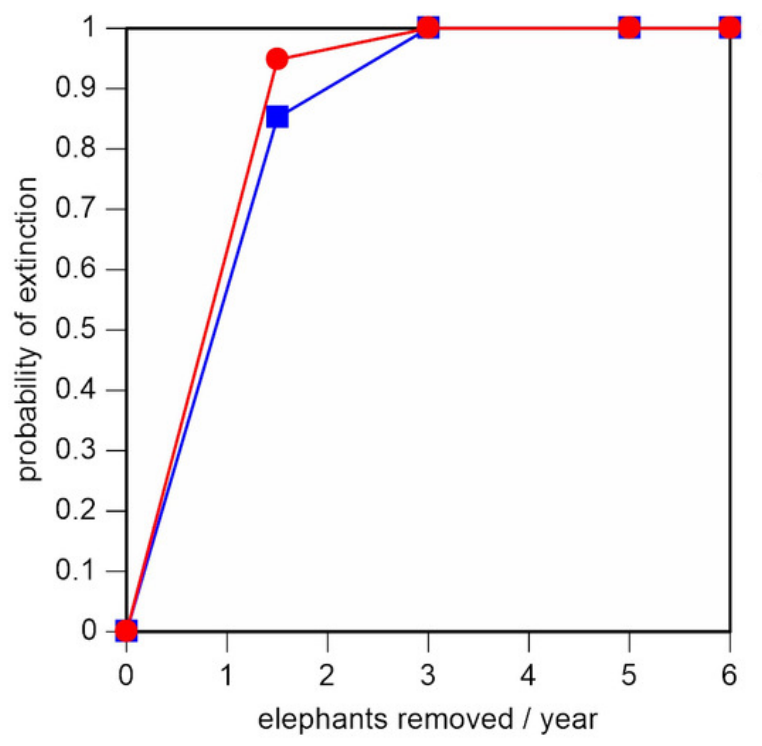

$\rightarrow \mathrm{NoQ} O \mathrm{C}$

$\longrightarrow$ NoQ 2C
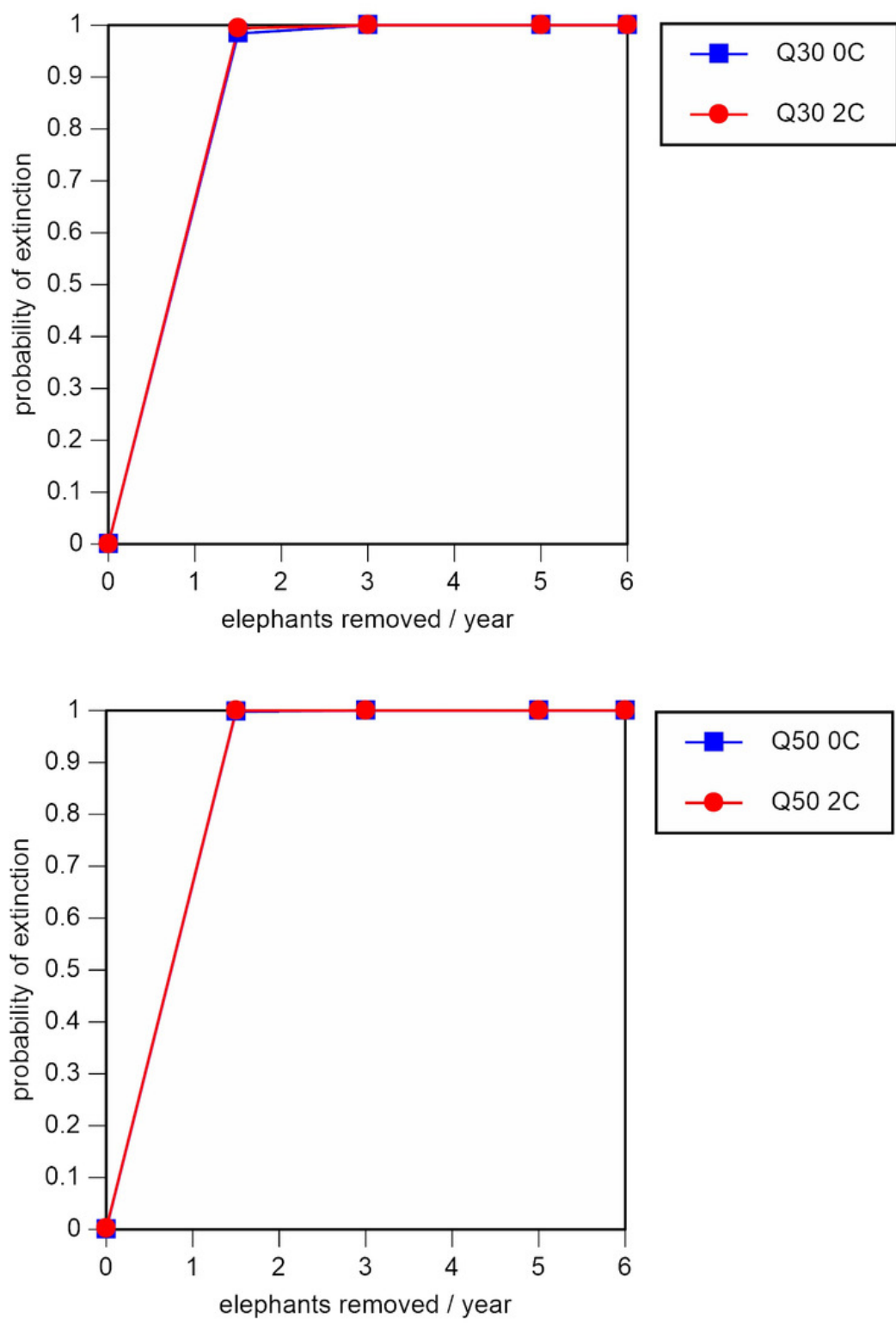

Peer] reviewing PDF | (2019:05:37435:1:1:NEW 8 Nov 2019) 


\section{Figure 5}

Figure 5. Results of the population viability analysis for the most optimistic scenarios (natality rate of 0.20 offspring/mature female/year, mortality rates reduced by $20 \%$, all other parameter values the same as in the baseline scenarios), showing the ef

For values see Table 6 and for terms used see Table 1. 

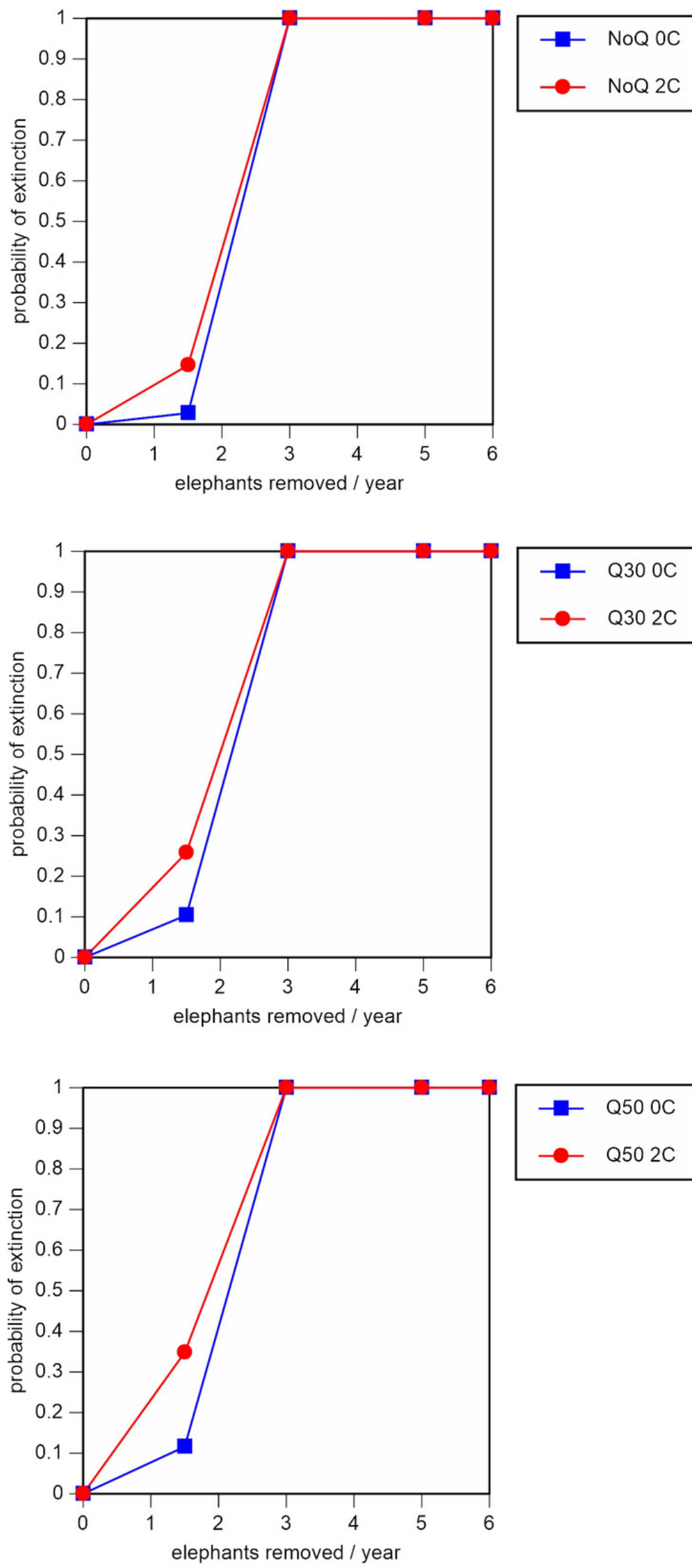

$-\mathrm{Q} 500 \mathrm{C}$

$\rightarrow$ Q502C 
Figure 6

Figure 6. Results of the sensitivity analysis for the PVA models with mortality rates reduced by $20 \%$ and three different natality rates (a) 0.16 offspring/mature female/year, (b) 0.18 offspring/mature female/year, and (c) 0.20 offspring/mature female/year

For values see the Supplemental Information and for terms used see Table 1.
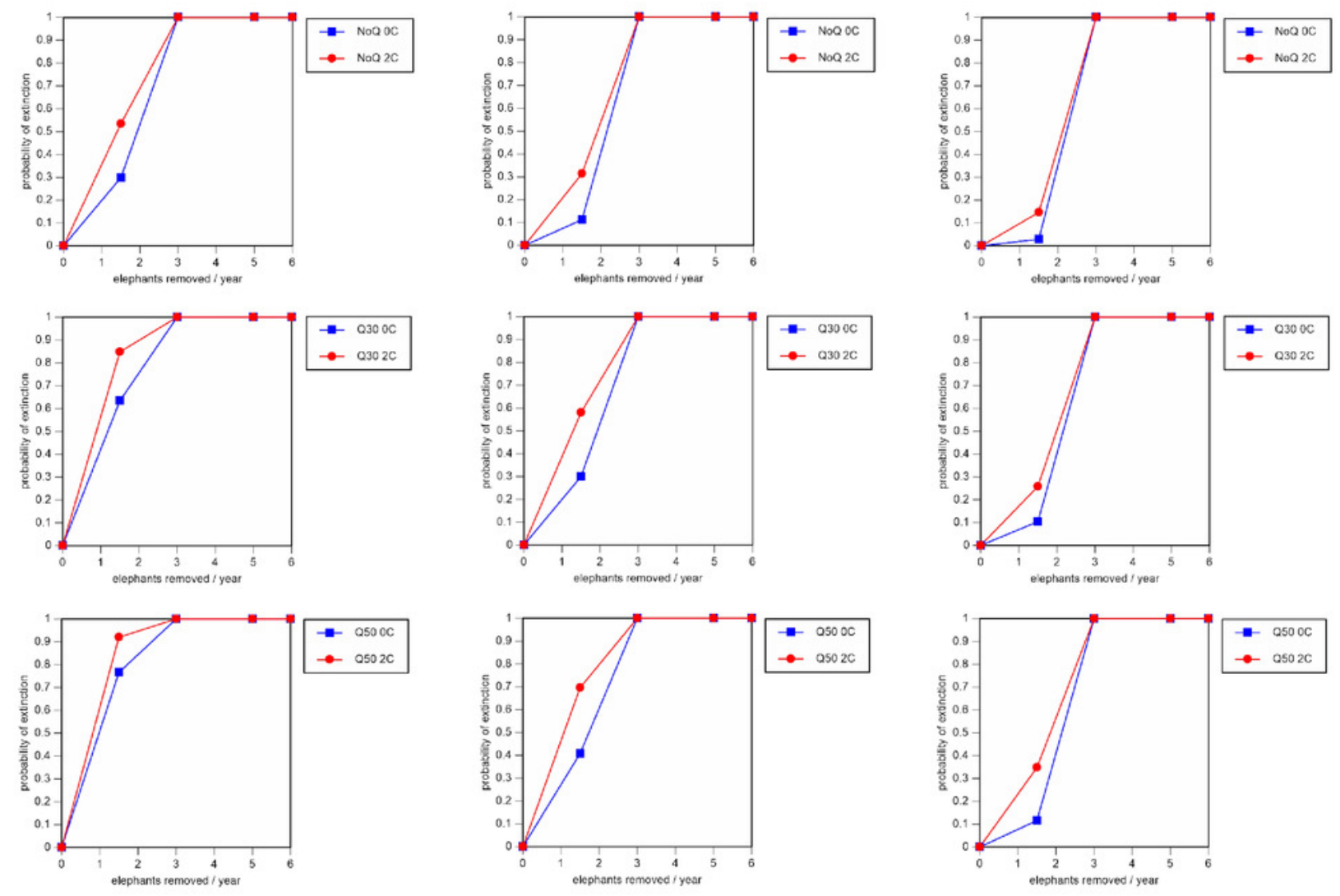

a

b

c 
Figure 7

Figure 7. Results of the sensitivity analysis for the PVA models with baseline mortality rates and three different natality rates (a) 0.16 offspring/mature female/year, (b) 0.18 offspring/mature female/year, and (c) 0.20 offspring/mature female/year (all

For values see the Supplemental Information and for terms used see Table 1.
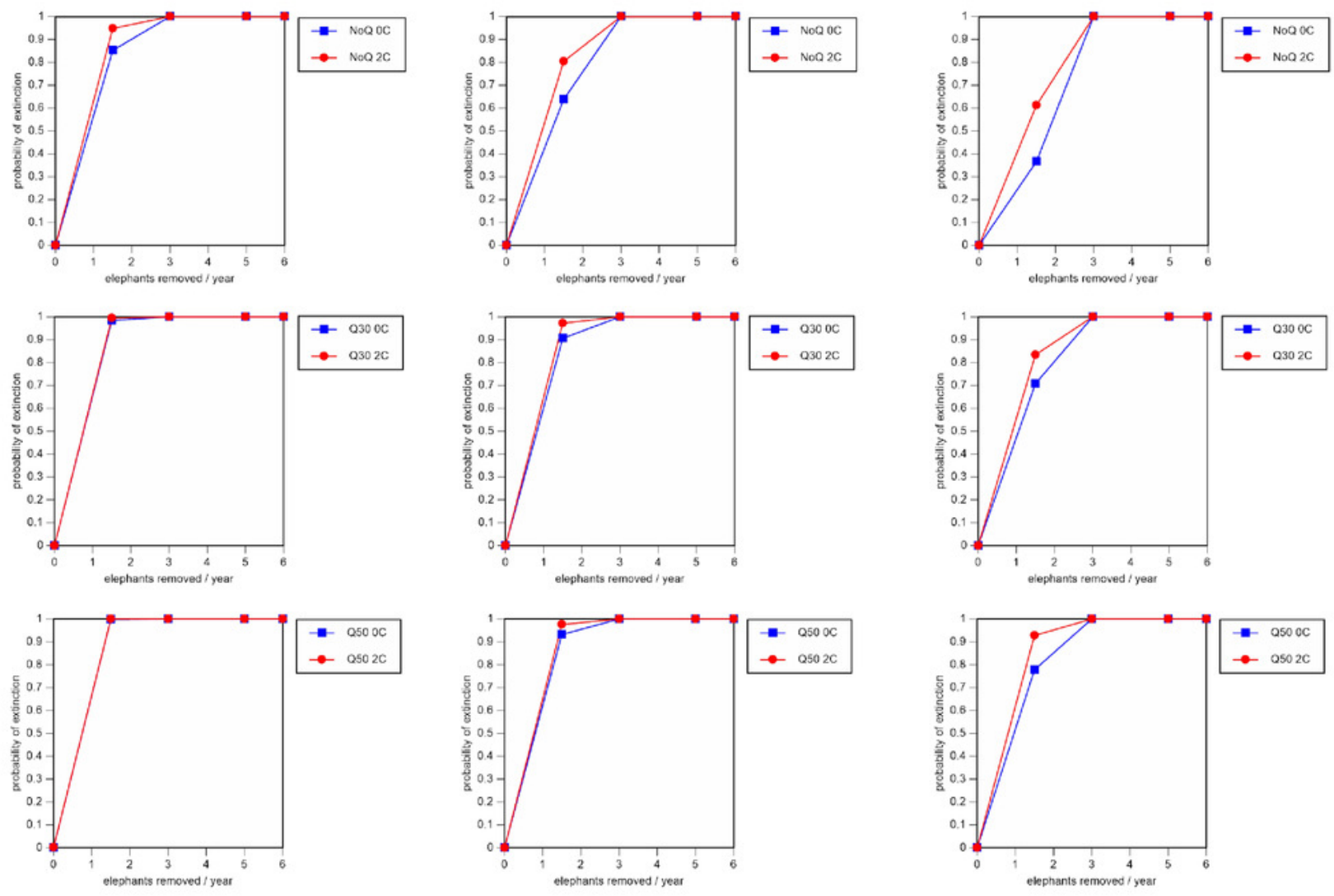

a

b

c 
Figure 8

Figure 8 . Results of the sensitivity analysis for the PVA models with mortality rates increased by $20 \%$ and three different natality rates (a) 0.16 offspring/mature female/year, (b) 0.18 offspring/mature female/year, and (c) 0.20 offspring/mature female/ye

For values see the Supplemental Information and for terms used see Table 1.
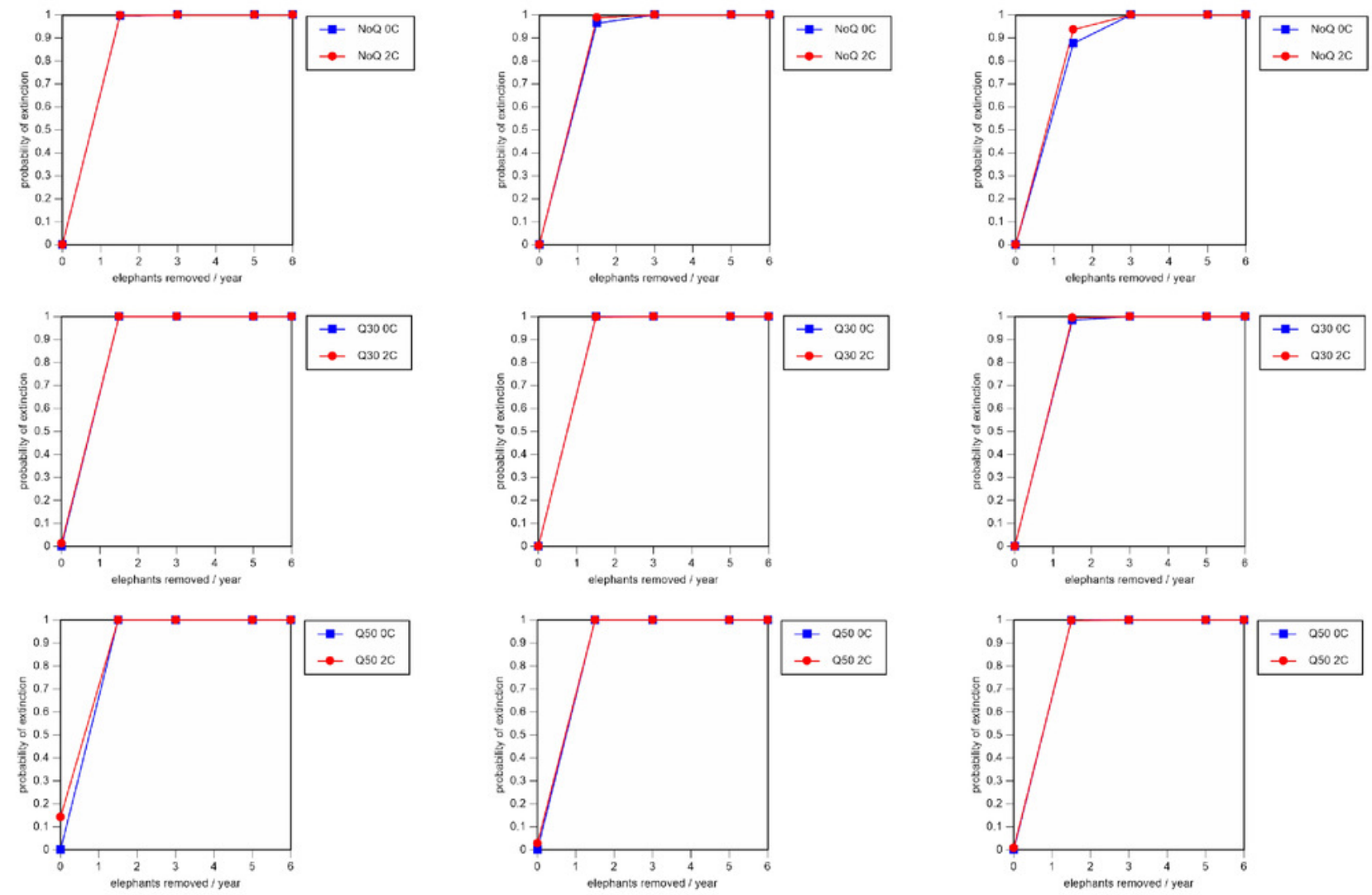


\section{Table $\mathbf{1}$ (on next page)}

Table 1: Terms used in Figures 3 to 8, Tables 5 to 7 , and S1. 


\begin{tabular}{|c|c|}
\hline \multicolumn{2}{|c|}{ Terms used in Figures 3-8, Tables 5-7, and Table S1 in the Supplemental Information } \\
\hline & Abbreviations used in scenario names and figure legends \\
\hline FB & Female breeding rate $(\%)$ \\
\hline BaseMort & Baseline mortality rates (Table 1$)$ \\
\hline $\begin{array}{l}\text { No removal, very low } \\
\text { removal, etc. }\end{array}$ & Elephant removal rate for translocation (see Table 2) \\
\hline Mort $20 \%$ lower & Baseline mortality rates reduced by $20 \%$ (Table 3 ) \\
\hline Mort $20 \%$ higher & Baseline mortality rates increased by $20 \%$ (Table 3 ) \\
\hline $0 \mathrm{C}$ and $2 \mathrm{C}$ & No and 2 types of catastrophe (flood and disease), respectively \\
\hline NoQ, Q30, Q50 & No quasi-extinction and quasi-extinction at 30 and 50 individuals, respectively \\
\hline \multicolumn{2}{|r|}{ Column-head abbreviations } \\
\hline det-r & the mean population deterministic growth rate, $r$ \\
\hline stoc-r & the mean population stochastic growth rate, $r$ \\
\hline $\mathrm{SD}(\mathrm{r})$ & standard deviation of the stochastic growth rate \\
\hline $\mathrm{PE}$ & the final probability of population extinction \\
\hline N-ext & the mean final population size for those iterations that do not become extinct \\
\hline $\mathrm{SD}(\mathrm{n}-\mathrm{ext})$ & $\begin{array}{l}\text { the standard deviation for the mean final population size for those iterations that do not } \\
\text { become extinct }\end{array}$ \\
\hline $\mathrm{N}$-all & $\begin{array}{l}\text { the mean final population size for all populations, including those that went extinct (e.g. } \\
\text { had a final size of } 0 \text { ) }\end{array}$ \\
\hline $\mathrm{SD}(\mathrm{N}-\mathrm{all})$ & the standard deviation for $\mathrm{N}$-all \\
\hline MedianTE & If at least $50 \%$ of the iterations went extinct, the median time to extinction in years; \\
\hline MeanTE & $\begin{array}{l}\text { Of those iterations that experience extinctions, the mean time to first population } \\
\text { extinction (in years) }\end{array}$ \\
\hline
\end{tabular}




\section{Table 2 (on next page)}

Table 2: Baseline parameter values used for modeling the Endau Rompin Landscape elephant population. 


\begin{tabular}{|c|c|c|}
\hline Input parameter & Value & Source/justification \\
\hline \multicolumn{3}{|l|}{ General parameters } \\
\hline Number of years & 100 & Following Tilson et al. (1994); also see Discussion section. \\
\hline Time-steps & 1 year & Following Tilson et al. (1994) and Leimgruber et al. (2008). \\
\hline Number of iterations & 500 & $\begin{array}{l}\text { Following Tilson et al. (1994); 500-1000 iterations are typical values in VORTEX models (Miller \& Lacy } \\
\text { (2005). }\end{array}$ \\
\hline Extinction definition & $\begin{array}{r}\text { Only } 1 \text { sex } \\
\text { remains }\end{array}$ & $\begin{array}{l}\text { Following Tilson et al. (1994) and Leimgruber } \text { et al. (2008), this is the standard definition of extinction in } \\
\text { PVA analyses; two levels of quasi-extinction were also modeled, see text for further discussion. }\end{array}$ \\
\hline \multicolumn{3}{|r|}{ P } \\
\hline Age of first offspring for females (years) & 20 & $\begin{array}{l}\text { Following Tilson et al. (1994) who argue that females tend to breed later in rainforest areas compared to the } \\
\text { more open areas of southern India. }\end{array}$ \\
\hline Age of first offspring for males (years) & 20 & Following Tilson et al. (1994). \\
\hline Maximum age of reproduction (years) & 60 & Following Tilson et al. (1994), Sukumar (2003), and Leimgruber et al. (2008). \\
\hline Maximum number of progeny per year & 1 & Following Tilson et al. (1994), Sukumar (2003), and Leimgruber et al. (2008). \\
\hline Sex ratio at birth & $1: 1$ & Following Tilson et al. (1994) and Leimgruber et al. (2008). \\
\hline Density-dependent reproduction & No & Following Tilson et al. (1994) and Leimgruber et al. (2008). \\
\hline \multicolumn{3}{|l|}{ Reproductive rates } \\
\hline offspring/mature female/year & 0.18 & Following Tilson et al. (1994) and Leimgruber et al. (2008). \\
\hline Environmental variation in breeding & $3.20 \%$ & Approximately $20 \%$ of the mean value following Tilson et al. (1994) and Leimgruber et al. (2008). \\
\hline \multicolumn{3}{|l|}{ Mortality rates for females } \\
\hline $0-1$ years & $15.00 \%$ & Following Tilson et al. (1994), Sukumar (2003), and Leimgruber et al. (2008). \\
\hline$>1-5$ & $4.00 \%$ & Following Tilson et al. (1994) and Leimgruber et al. (2008). \\
\hline$>5-15$ & $2.00 \%$ & Following Tilson et al. (1994) and Leimgruber et al. (2008). \\
\hline$>15$ & $2.50 \%$ & Following Tilson et al. (1994) and Leimgruber et al. (2008). \\
\hline \multicolumn{3}{|l|}{ Mortality rates for males } \\
\hline $0-1$ & $15.00 \%$ & Following Tilson et al. (1994), Sukumar (2003), and Leimgruber et al. (2008). \\
\hline$>1-5$ & $5.00 \%$ & Following Tilson et al. (1994) and Leimgruber et al. (2008). \\
\hline$>5-15$ & $3.00 \%$ & Following Sukumar (2003) and Leimgruber et al. (2008). \\
\hline$>15$ & $3.00 \%$ & Following Sukumar (2003) and Leimgruber et al. (2008). \\
\hline \multicolumn{3}{|r|}{ 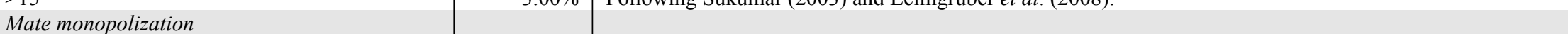 } \\
\hline Percent males in breeding pool & $80 \%$ & Following Tilson et al. (1994) and Leimgruber et al. (2008). \\
\hline \multicolumn{3}{|l|}{ Initial population } \\
\hline $\begin{array}{l}\text { Start with age distribution } \\
\text { Initial population size }\end{array}$ & $\begin{array}{r}\text { Stable } \\
135\end{array}$ & $\begin{array}{l}\text { Following Tilson et al. (1994) and Leimgruber et al. (2008); also see Table } 3 \\
\text { This studv. }\end{array}$ \\
\hline \multicolumn{3}{|l|}{ Carrying capacity } \\
\hline Carrying capacity $(\mathrm{K})$ & 250 & Calculate from area of ERL using 0.1 elephant/sq km after Sukumar (2003) \\
\hline $\mathrm{SD}$ in $\mathrm{K}$ due to environmental variation & 5 & Following Leimgruber et al. (2008). \\
\hline Trend in $\mathrm{K}$ ? & No & $\begin{array}{l}\text { Following Leimgruber et al. (2008) and most of the Tilson et al. (1994) scenarios; see text for further } \\
\text { justification. }\end{array}$ \\
\hline \multicolumn{3}{|r|}{ 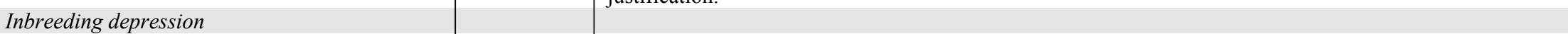 } \\
\hline Lethal equivalents & 3.14 & Following Tilson et al. (1994) and Miller and Lacy (2005); the value is the mean for 40 mammalian species. \\
\hline Percent due to recessive lethals & 50 & Following Tilson et al. (1994) and Miller and Lacy (2005); the value is the mean for 40 mammalian species. \\
\hline
\end{tabular}




\section{Table 3 (on next page)}

Table 3. Elephant removal rates included in the population viability models. 
1

\begin{tabular}{|c|c|c|c|c|c|c|}
\hline Scenario & Frequency & $\begin{array}{r}\text { Total number } \\
\text { of } \\
\text { elephants } \\
\text { removed }\end{array}$ & $\begin{array}{r}\text { Adult } \\
\text { females } \\
(\geq 20 \text { yrs } \\
\text { old })\end{array}$ & $\begin{array}{r}\text { Juvenile females } \\
\text { ( } \geq 5 \text { but }<20 \text { yrs } \\
\text { old })\end{array}$ & $\begin{array}{r}\text { Adult } \\
\text { males } \\
(\geq 20 \text { yrs } \\
\text { old })\end{array}$ & $\begin{array}{r}\text { Juvenile males } \\
(\geq 5 \text { but }<20 \text { yrs } \\
\text { old })\end{array}$ \\
\hline No removal & N/A & 0 & 0 & 0 & 0 & 0 \\
\hline $\begin{array}{l}\text { Very low } \\
\text { removal }\end{array}$ & $\begin{array}{l}\text { Every other } \\
\text { year }\end{array}$ & 3 & 2 & 0 & 1 & 0 \\
\hline Low removal & Every year & 3 & 2 & 0 & 1 & 0 \\
\hline $\begin{array}{l}\text { Medium } \\
\text { removal }\end{array}$ & $\begin{array}{l}\text { Every other } \\
\text { year }\end{array}$ & 10 & 4 & 2 & 2 & 2 \\
\hline High removal & Every year & 6 & 3 & 1 & 1 & 1 \\
\hline
\end{tabular}

2 


\section{Table 4 (on next page)}

Table 4. Male and female mortality rates used in the sensitivity analyses that were run to assess the robustness of the baseline models; three values for female breeding rate were also used in these analyses: $0.16,0.18$, and 0.20 offspring/mature female/y 
1

\begin{tabular}{|c|c|c|c|c|c|c|}
\hline \multirow{2}{*}{$\begin{array}{l}\text { Age class } \\
\text { (years) }\end{array}$} & \multicolumn{3}{|c|}{ Female mortality (\%) } & \multicolumn{3}{|c|}{ Male mortality (\%) } \\
\hline & Baseline rates & $\begin{array}{r}\text { Baseline rates } \\
\text { reduced by } \\
20 \%\end{array}$ & $\begin{array}{r}\text { Baseline rates } \\
\text { increased by } \\
20 \%\end{array}$ & Baseline rates & $\begin{array}{r}\text { Baseline rates } \\
\text { reduced by } \\
\mathbf{2 0 \%}\end{array}$ & $\begin{array}{r}\text { Baseline rates } \\
\text { increased by } \\
20 \%\end{array}$ \\
\hline $0-1(3 \mathrm{f} ; 3 \mathrm{~m})$ & $15.00 \%$ & $12.00 \%$ & $18.00 \%$ & $15.00 \%$ & $12.00 \%$ & $18.00 \%$ \\
\hline $\begin{array}{l}>1-5(9 \mathrm{f} \\
9 \mathrm{~m})\end{array}$ & $4.00 \%$ & $3.20 \%$ & $4.80 \%$ & $5.00 \%$ & $4.00 \%$ & $6.00 \%$ \\
\hline $\begin{array}{l}>5-15(19 f ; \\
17 \mathrm{~m})\end{array}$ & $2.00 \%$ & $1.60 \%$ & $2.40 \%$ & $3.00 \%$ & $2.40 \%$ & $3.60 \%$ \\
\hline $\begin{array}{l}>15(43 \mathrm{f} ; \\
32 \mathrm{~m})\end{array}$ & $2.50 \%$ & $2.00 \%$ & $3.00 \%$ & $3.00 \%$ & $2.40 \%$ & $3.60 \%$ \\
\hline
\end{tabular}

2 


\section{Table 5 (on next page)}

Table 5. Results of the population viability analysis for all baseline scenarios. See Table 1 for terms used.

See Table 1 for terms used. 


\begin{tabular}{|c|c|c|c|c|c|c|c|c|c|c|}
\hline Scenario name & det-r & stoc-r & SD(r) & PE & N-ext & SD(N-ext) & $\mathrm{N}$-all & SD(N-all) & MedianTE & MeanTE \\
\hline FB18\% + BaseMort $+0 \mathrm{C}+$ no removal + NoQ & 0.006 & 0.006 & 0.025 & 0.000 & 218.24 & 28.94 & 218.24 & 28.94 & 0 & 0.0 \\
\hline FB18\% + BaseMort + 0C + no removal + Q30 & 0.006 & 0.005 & 0.025 & 0.000 & 216.57 & 32.39 & 216.57 & 32.39 & 0 & 0.0 \\
\hline FB18\% + BaseMort + 0C + no removal + Q50 & 0.006 & 0.006 & 0.025 & 0.000 & 220.48 & 28.04 & 220.48 & 28.04 & 0 & 0.0 \\
\hline $\mathrm{FB} 18 \%+$ BaseMort $+2 \mathrm{C}+$ no removal $+\mathrm{NoQ}$ & 0.004 & 0.003 & 0.03 & 0.000 & 186.70 & 42.40 & 186.70 & 42.40 & 0 & 0.0 \\
\hline FB18\% + BaseMort + 2C + no removal + Q30 & 0.004 & 0.003 & 0.030 & 0.000 & 186.24 & 42.12 & 186.24 & 42.12 & 0 & 0.0 \\
\hline FB18\% + BaseMort + 2C + no removal + Q50 & 0.004 & 0.003 & 0.030 & 0.000 & 186.65 & 43.28 & 186.65 & 43.28 & 0 & 0.0 \\
\hline $\mathrm{FB} 18 \%+$ BaseMort $+0 \mathrm{C}+$ very low removal $+\mathrm{NoQ}$ & 0.006 & -0.032 & 0.067 & 0.638 & 27.24 & 25.53 & 10.27 & 20.02 & 93 & 85.4 \\
\hline $\mathrm{FB} 18 \%+$ BaseMort $+0 \mathrm{C}+$ very low removal $+\mathrm{Q} 30$ & 0.006 & -0.019 & 0.039 & 0.906 & 58.30 & 23.21 & 8.88 & 18.43 & 75 & 73.0 \\
\hline $\mathrm{FB} 18 \%+$ BaseMort $+0 \mathrm{C}+$ very low removal $+\mathrm{Q} 50$ & 0.006 & -0.015 & 0.034 & 0.932 & 66.62 & 12.76 & 9.01 & 18.08 & 63 & 63.2 \\
\hline FB $18 \%+$ BaseMort $+2 \mathrm{C}+$ very low removal + NoQ & 0.004 & -0.039 & 0.076 & 0.804 & 20.72 & 18.20 & 4.35 & 11.46 & 85 & 81.0 \\
\hline $\mathrm{FB} 18 \%+$ BaseMort $+2 \mathrm{C}+$ very low removal $+\mathrm{Q} 30$ & 0.004 & -0.022 & 0.042 & 0.972 & 46.50 & 13.84 & 2.98 & 8.82 & 65 & 66.0 \\
\hline $\mathrm{FB} 18 \%+$ BaseMort $+2 \mathrm{C}+$ very low removal $+\mathrm{Q} 50$ & 0.004 & -0.017 & 0.037 & 0.976 & 61.08 & 12.29 & 3.93 & 11.61 & 55 & 56.6 \\
\hline $\mathrm{FB} 18 \%+$ BaseMort $+0 \mathrm{C}+$ low removal + NoQ & 0.006 & -0.078 & 0.087 & 1.000 & 0.00 & 0.00 & 0.00 & 0.00 & 46 & 46.5 \\
\hline $\mathrm{FB} 18 \%+$ BaseMort $+0 \mathrm{C}+$ low removal $+\mathrm{Q} 30$ & 0.006 & -0.046 & 0.037 & 1.000 & 0.00 & 0.00 & 0.00 & 0.00 & 33 & 33.0 \\
\hline $\mathrm{FB} 18 \%+$ BaseMort $+0 \mathrm{C}+$ low removal $+\mathrm{Q} 50$ & 0.006 & -0.037 & 0.031 & 1.000 & 0.00 & 0.00 & 0.00 & 0.00 & 27 & 27.0 \\
\hline FB $18 \%+$ BaseMort $+2 \mathrm{C}+$ low removal + NoQ & 0.004 & -0.082 & 0.09 & 1.000 & 0.00 & 0.00 & 0.00 & 0.00 & 45 & 44.6 \\
\hline FB18\% + BaseMort $+2 \mathrm{C}+$ low removal $+\mathrm{Q} 30$ & 0.004 & -0.048 & 0.04 & 1.000 & 0.00 & 0.00 & 0.00 & 0.00 & 31 & 31.5 \\
\hline FB18\% + BaseMort + 2C + low removal + Q50 & 0.004 & -0.038 & 0.034 & 1.000 & 0.00 & 0.00 & 0.00 & 0.00 & 25 & 25.9 \\
\hline $\mathrm{FB} 18 \%+$ BaseMort $+0 \mathrm{C}+$ medium removal + NoQ & 0.006 & -0.097 & 0.138 & 1.000 & 0.00 & 0.00 & 0.00 & 0.00 & 37 & 37.7 \\
\hline $\mathrm{FB} 18 \%+$ BaseMort $+0 \mathrm{C}+$ medium removal $+\mathrm{Q} 30$ & 0.006 & -0.058 & 0.07 & 1.000 & 0.00 & 0.00 & 0.00 & 0.00 & 25 & 25.3 \\
\hline $\mathrm{FB} 18 \%+$ BaseMort $+0 \mathrm{C}+$ medium removal $+\mathrm{Q} 50$ & 0.006 & -0.048 & 0.059 & 1.000 & 0.00 & 0.00 & 0.00 & 0.00 & 20 & 20.2 \\
\hline $\mathrm{FB} 18 \%+$ BaseMort $+2 \mathrm{C}+$ medium removal $+\mathrm{NoQ}$ & 0.004 & -0.099 & 0.137 & 1.000 & 0.00 & 0.00 & 0.00 & 0.00 & 37 & 36.8 \\
\hline $\mathrm{FB} 18 \%+$ BaseMort $+2 \mathrm{C}+$ medium removal $+\mathrm{Q} 30$ & 0.004 & -0.061 & 0.073 & 1.000 & 0.00 & 0.00 & 0.00 & 0.00 & 25 & 24.2 \\
\hline $\mathrm{FB} 18 \%+$ BaseMort $+2 \mathrm{C}+$ medium removal $+\mathrm{Q} 50$ & 0.004 & -0.05 & 0.06 & 1.000 & 0.00 & 0.00 & 0.00 & 0.00 & 19 & 19.3 \\
\hline $\mathrm{FB} 18 \%+$ BaseMort $+0 \mathrm{C}+$ high removal $+\mathrm{NoQ}$ & 0.006 & -0.105 & 0.073 & 1.000 & 0.00 & 0.00 & 0.00 & 0.00 & 28 & 28.1 \\
\hline $\mathrm{FB} 18 \%+$ BaseMort $+0 \mathrm{C}+$ high removal $+\mathrm{Q} 30$ & 0.006 & -0.08 & 0.044 & 1.000 & 0.00 & 0.00 & 0.00 & 0.00 & 19 & 19.1 \\
\hline FB18\% + BaseMort + 0C + high removal + Q50 & 0.006 & -0.067 & 0.036 & 1.000 & 0.00 & 0.00 & 0.00 & 0.00 & 15 & 15.1 \\
\hline $\mathrm{FB} 18 \%+$ BaseMort $+2 \mathrm{C}+$ high removal $+\mathrm{NoQ}$ & 0.004 & -0.111 & 0.082 & 1.000 & 0.00 & 0.00 & 0.00 & 0.00 & 28 & 27.9 \\
\hline $\mathrm{FB} 18 \%+$ BaseMort $+2 \mathrm{C}+$ high removal $+\mathrm{Q} 30$ & 0.004 & -0.082 & 0.046 & 1.000 & 0.00 & 0.00 & 0.00 & 0.00 & 19 & 18.6 \\
\hline FB18\% + BaseMort $+2 \mathrm{C}+$ high removal $+\mathrm{Q} 50$ & 0.004 & -0.068 & 0.038 & 1.000 & 0.00 & 0.00 & 0.00 & 0.00 & 15 & 14.7 \\
\hline
\end{tabular}




\section{Table 6(on next page)}

Table 6. Results of the population viability analysis for all reduced female breeding rate scenarios ( 0.16 offspring/mature female/year, all other parameter values the same as in the baseline scenarios). See Table 1 for terms used.

See Table 1 for terms used. 


\begin{tabular}{|c|c|c|c|c|c|c|c|c|c|c|}
\hline Scenario name & det-r & stoc-r & SD(r) & $\mathbf{P E}$ & N-ext & SD(N-ext) & N-all & SD(N-all) & MedianTE & MeanTE \\
\hline $\mathrm{FB} 16 \%+$ BaseMort $+0 \mathrm{C}+$ no removal $+\mathrm{NoQ}$ & 0.003 & 0.002 & 0.025 & 0.000 & 174.02 & 38.02 & 174.02 & 38.02 & 0 & 0.0 \\
\hline $\mathrm{FB} 16 \%+$ BaseMort $+0 \mathrm{C}+$ no removal $+\mathrm{Q} 30$ & 0.003 & 0.002 & 0.025 & 0.000 & 172.47 & 38.53 & 172.47 & 38.53 & 0 & 0.0 \\
\hline $\mathrm{FB} 16 \%+$ BaseMort $+0 \mathrm{C}+$ no removal $+\mathrm{Q} 50$ & 0.003 & 0.002 & 0.025 & 0.000 & 175.00 & 38.33 & 175.00 & 38.33 & 0 & 0.0 \\
\hline $\mathrm{FB} 16 \%+$ BaseMort $+2 \mathrm{C}+$ no removal + NoQ & 0.000 & 0.000 & 0.031 & 0.000 & 139.21 & 38.83 & 139.21 & 38.83 & 0 & 0.0 \\
\hline $\mathrm{FB} 16 \%+$ BaseMort $+2 \mathrm{C}+$ no removal $+\mathrm{Q} 30$ & 0.000 & 0.000 & 0.030 & 0.000 & 136.88 & 40.24 & 136.88 & 40.24 & 0 & 0.0 \\
\hline $\mathrm{FB} 16 \%+$ BaseMort $+2 \mathrm{C}+$ no removal $+\mathrm{Q} 50$ & 0.000 & 0.000 & 0.030 & 0.002 & 144.00 & 39.27 & 143.79 & 39.52 & 0 & 71.0 \\
\hline $\mathrm{FB} 16 \%+$ BaseMort $+0 \mathrm{C}+$ very low removal + NoQ & 0.003 & -0.041 & 0.076 & 0.852 & 12.38 & 11.33 & 2.07 & 6.19 & 83 & 81.2 \\
\hline $\mathrm{FB} 16 \%+$ BaseMort $+0 \mathrm{C}+$ very low removal $+\mathrm{Q} 30$ & 0.003 & -0.022 & 0.040 & 0.984 & 54.25 & 27.61 & 2.07 & 8.21 & 64 & 65.6 \\
\hline FB16\% + BaseMort $+0 \mathrm{C}+$ very low removal $+\mathrm{Q} 50$ & 0.003 & -0.017 & 0.034 & 0.998 & 91.00 & 0.00 & 2.03 & 6.85 & 55 & 55.9 \\
\hline $\mathrm{FB} 16 \%+$ BaseMort $+2 \mathrm{C}+$ very low removal $+\mathrm{NoQ}$ & 0.000 & -0.045 & 0.081 & 0.948 & 10.23 & 7.98 & 0.63 & 2.90 & 77 & 77.1 \\
\hline $\mathrm{FB} 16 \%+$ BaseMort $+2 \mathrm{C}+$ very low removal $+\mathrm{Q} 30$ & 0.000 & -0.025 & 0.042 & 0.994 & 44.00 & 10.58 & 0.92 & 4.26 & 59 & 60.1 \\
\hline FB16\% + BaseMort $+2 \mathrm{C}+$ very low removal $+\mathrm{Q} 50$ & 0.000 & -0.020 & 0.037 & 1.000 & 0.00 & 0.00 & 0.71 & 2.98 & 49 & 49.4 \\
\hline $\mathrm{FB} 16 \%+$ BaseMort $+0 \mathrm{C}+$ low removal + NoQ & 0.003 & -0.082 & 0.088 & 1.000 & 0.00 & 0.00 & 0.00 & 0.00 & 44 & 44.4 \\
\hline $\mathrm{FB} 16 \%+$ BaseMort $+0 \mathrm{C}+$ low removal $+\mathrm{Q} 30$ & 0.003 & -0.048 & 0.037 & 1.000 & 0.00 & 0.00 & 0.00 & 0.00 & 31 & 31.4 \\
\hline $\mathrm{FB} 16 \%+$ BaseMort $+0 \mathrm{C}+$ low removal $+\mathrm{Q} 50$ & 0.003 & -0.038 & 0.031 & 1.000 & 0.00 & 0.00 & 0.00 & 0.00 & 26 & 26.0 \\
\hline FB16\% + BaseMort $+2 \mathrm{C}+$ low removal + NoQ & 0.000 & -0.086 & 0.093 & 1.000 & 0.00 & 0.00 & 0.00 & 0.00 & 43 & 42.8 \\
\hline $\mathrm{FB} 16 \%+$ BaseMort $+2 \mathrm{C}+$ low removal $+\mathrm{Q} 30$ & 0.000 & -0.050 & 0.040 & 1.000 & 0.00 & 0.00 & 0.00 & 0.00 & 30 & 30.0 \\
\hline FB16\% + BaseMort $+2 \mathrm{C}+$ low removal $+\mathrm{Q} 50$ & 0.000 & -0.041 & 0.034 & 1.000 & 0.00 & 0.00 & 0.00 & 0.00 & 25 & 24.5 \\
\hline $\mathrm{FB} 16 \%+$ BaseMort $+0 \mathrm{C}+$ medium removal $+\mathrm{NoQ}$ & 0.003 & -0.100 & 0.138 & 1.000 & 0.00 & 0.00 & 0.00 & 0.00 & 37 & 36.5 \\
\hline $\mathrm{FB} 16 \%+$ BaseMort $+0 \mathrm{C}+$ medium removal $+\mathrm{Q} 30$ & 0.003 & -0.060 & 0.071 & 1.000 & 0.00 & 0.00 & 0.00 & 0.00 & 25 & 24.3 \\
\hline $\mathrm{FB} 16 \%+$ BaseMort $+0 \mathrm{C}+$ medium removal $+\mathrm{Q} 50$ & 0.003 & -0.050 & 0.059 & 1.000 & 0.00 & 0.00 & 0.00 & 0.00 & 19 & 19.5 \\
\hline $\mathrm{FB} 16 \%+$ BaseMort $+2 \mathrm{C}+$ medium removal + NoQ & 0.000 & -0.102 & 0.140 & 1.000 & 0.00 & 0.00 & 0.00 & 0.00 & 36 & 36.0 \\
\hline $\mathrm{FB} 16 \%+$ BaseMort $+2 \mathrm{C}+$ medium removal $+\mathrm{Q} 30$ & 0.000 & -0.063 & 0.073 & 1.000 & 0.00 & 0.00 & 0.00 & 0.00 & 23 & 23.4 \\
\hline $\mathrm{FB} 16 \%+$ BaseMort $+2 \mathrm{C}+$ medium removal $+\mathrm{Q} 50$ & 0.000 & -0.053 & 0.061 & 1.000 & 0.00 & 0.00 & 0.00 & 0.00 & 19 & 18.4 \\
\hline $\mathrm{FB} 16 \%+$ BaseMort $+0 \mathrm{C}+$ high removal $+\mathrm{NoQ}$ & 0.003 & -0.110 & 0.081 & 1.000 & 0.00 & 0.00 & 0.00 & 0.00 & 28 & 28.1 \\
\hline FB16\% + BaseMort + 0C + high removal + Q30 & 0.003 & -0.082 & 0.045 & 1.000 & 0.00 & 0.00 & 0.00 & 0.00 & 19 & 18.5 \\
\hline FB16\% + BaseMort $+0 \mathrm{C}+$ high removal + Q50 & 0.003 & -0.069 & 0.035 & 1.000 & 0.00 & 0.00 & 0.00 & 0.00 & 15 & 14.6 \\
\hline FB16\% + BaseMort $+2 \mathrm{C}+$ high removal + NoQ & 0.000 & -0.112 & 0.082 & 1.000 & 0.00 & 0.00 & 0.00 & 0.00 & 28 & 27.4 \\
\hline FB16\% + BaseMort $+2 \mathrm{C}+$ high removal $+\mathrm{Q} 30$ & 0.000 & -0.084 & 0.047 & 1.000 & 0.00 & 0.00 & 0.00 & 0.00 & 18 & 18.2 \\
\hline FB16\% + BaseMort $+2 \mathrm{C}+$ high removal + Q 50 & 0.000 & -0.071 & 0.038 & 1.000 & 0.00 & 0.00 & 0.00 & 0.00 & 14 & 14.3 \\
\hline
\end{tabular}




\section{Table 7 (on next page)}

Table 7. Results of the population viability analysis for the most optimistic scenarios ( 0.20 offspring/mature female/year, mortality rates reduced by $20 \%$, all other parameter values the same as in the baseline scenarios). See Table 1 for terms used.

See Table 1 for terms used. 


\begin{tabular}{|c|c|c|c|c|c|c|c|c|c|c|}
\hline Scenario name & det-r & stoc-r & SD(r) & $\mathbf{P E}$ & N-ext & SD(N-ext) & $\mathrm{N}$-all & SD(N-all) & MedianTE & MeanTE \\
\hline FB20\% + Mort $20 \%$ lower $+0 \mathrm{C}+$ no removal + NoQ & 0.015 & 0.014 & 0.022 & 0.000 & 244.43 & 5.80 & 244.43 & 5.80 & 0 & 0.0 \\
\hline FB20\% + Mort20\%lower $+0 \mathrm{C}+$ no removal $+\mathrm{Q} 30$ & 0.015 & 0.015 & 0.022 & 0.000 & 244.68 & 5.88 & 244.68 & 5.88 & 0 & 0.0 \\
\hline FB20\% + Mort20\%lower + 0C + no removal + Q50 & 0.015 & 0.015 & 0.022 & 0.000 & 244.71 & 5.53 & 244.71 & 5.53 & 0 & 0.0 \\
\hline FB20\% + Mort $20 \%$ lower $+2 \mathrm{C}+$ no removal + NoQ & 0.013 & 0.012 & 0.027 & 0.000 & 241.42 & 10.73 & 241.42 & 10.73 & 0 & 0.0 \\
\hline FB20\% + Mort $20 \%$ lower $+2 \mathrm{C}+$ no removal $+\mathrm{Q} 30$ & 0.013 & 0.012 & 0.027 & 0.000 & 242.10 & 9.31 & 242.10 & 9.31 & 0 & 0.0 \\
\hline FB20\% + Mort20\%lower + 2C + no removal + Q50 & 0.013 & 0.012 & 0.027 & 0.000 & 242.13 & 8.66 & 242.13 & 8.66 & 0 & 0.0 \\
\hline FB $20 \%+$ Mort $20 \%$ lower $+0 \mathrm{C}+$ very low removal + NoQ & 0.015 & -0.002 & 0.031 & 0.028 & 137.99 & 66.06 & 134.15 & 68.96 & 0 & 87.1 \\
\hline FB20\% + Mort $20 \%$ lower $+0 \mathrm{C}+$ very low removal $+\mathrm{Q} 30$ & 0.015 & -0.002 & 0.029 & 0.104 & 139.55 & 60.88 & 126.76 & 68.87 & 0 & 90.4 \\
\hline FB20\% + Mort $20 \%$ lower $+0 \mathrm{C}+$ very low removal + Q50 & 0.015 & -0.001 & 0.028 & 0.116 & 147.13 & 57.15 & 132.86 & 66.87 & 0 & 83.8 \\
\hline FB $20 \%+$ Mort $20 \%$ lower $+2 \mathrm{C}+$ very low removal + NoQ & 0.013 & -0.011 & 0.044 & 0.146 & 90.35 & 61.38 & 77.34 & 64.88 & 0 & 88.2 \\
\hline FB20\% + Mort $20 \%$ lower $+2 \mathrm{C}+$ very low removal $+\mathrm{Q} 30$ & 0.013 & -0.007 & 0.035 & 0.258 & 107.03 & 53.12 & 81.46 & 63.21 & 0 & 81.1 \\
\hline FB20 $\%+$ Mort $20 \%$ lower $+2 \mathrm{C}+$ very low removal + Q50 & 0.013 & -0.005 & 0.033 & 0.348 & 121.13 & 52.93 & 84.41 & 66.54 & 0 & 76.4 \\
\hline FB20\% + Mort $20 \%$ lower $+0 \mathrm{C}+$ low removal + NoQ & 0.015 & -0.062 & 0.075 & 1.000 & 0.00 & 0.00 & 0.00 & 0.00 & 52 & 52.6 \\
\hline FB20\% + Mort $20 \%$ lower $+0 \mathrm{C}+$ low removal + Q30 & 0.015 & -0.036 & 0.035 & 1.000 & 0.00 & 0.00 & 0.00 & 0.00 & 41 & 41.3 \\
\hline FB20\% + Mort $20 \%$ lower + 0C + low removal + Q50 & 0.015 & -0.028 & 0.030 & 1.000 & 0.00 & 0.00 & 0.00 & 0.00 & 35 & 35.3 \\
\hline FB20\% + Mort $20 \%$ lower $+2 \mathrm{C}+$ low removal + NoQ & 0.013 & -0.067 & 0.080 & 1.000 & 0.00 & 0.00 & 0.00 & 0.00 & 50 & 50.4 \\
\hline FB20\% + Mort $20 \%$ lower $+2 \mathrm{C}+$ low removal $+\mathrm{Q} 30$ & 0.013 & -0.039 & 0.039 & 1.000 & 0.00 & 0.00 & 0.00 & 0.00 & 38 & 38.3 \\
\hline FB20\% + Mort $20 \%$ lower $+2 \mathrm{C}+$ low removal + Q50 & 0.013 & -0.030 & 0.032 & 1.000 & 0.00 & 0.00 & 0.00 & 0.00 & 32 & 32.6 \\
\hline FB $20 \%+$ Mort $20 \%$ lower $+0 \mathrm{C}+$ medium removal + NoQ & 0.015 & -0.081 & 0.120 & 1.000 & 0.00 & 0.00 & 0.00 & 0.00 & 41 & 41.1 \\
\hline FB20\% + Mort $20 \%$ lower $+0 \mathrm{C}+$ medium removal $+\mathrm{Q} 30$ & 0.015 & -0.050 & 0.068 & 1.000 & 0.00 & 0.00 & 0.00 & 0.00 & 29 & 29.3 \\
\hline FB20 $\%+$ Mort $20 \%$ lower $+0 \mathrm{C}+$ medium removal + Q50 & 0.015 & -0.041 & 0.057 & 1.000 & 0.00 & 0.00 & 0.00 & 0.00 & 23 & 23.8 \\
\hline FB2 $2 \%+$ Mort $20 \%$ lower $+2 \mathrm{C}+$ medium removal + NoQ & 0.013 & -0.086 & 0.125 & 1.000 & 0.00 & 0.00 & 0.00 & 0.00 & 39 & 39.9 \\
\hline FB20\% + Mort $20 \%$ lower $+2 \mathrm{C}+$ medium removal $+\mathrm{Q} 30$ & 0.013 & -0.053 & 0.070 & 1.000 & 0.00 & 0.00 & 0.00 & 0.00 & 27 & 27.8 \\
\hline FB20\% + Mort $20 \%$ lower $+2 \mathrm{C}+$ medium removal $+\mathrm{Q} 50$ & 0.013 & -0.043 & 0.059 & 1.000 & 0.00 & 0.00 & 0.00 & 0.00 & 23 & 22.7 \\
\hline FB20\% + Mort $20 \%$ lower $+0 \mathrm{C}+$ high removal + NoQ & 0.015 & -0.087 & 0.060 & 1.000 & 0.00 & 0.00 & 0.00 & 0.00 & 30 & 29.7 \\
\hline FB20\% + Mort20\%lower + 0C + high removal + Q30 & 0.015 & -0.070 & 0.041 & 1.000 & 0.00 & 0.00 & 0.00 & 0.00 & 22 & 21.7 \\
\hline FB20 $\%+$ Mort $20 \%$ lower + 0C + high removal + Q50 & 0.015 & -0.060 & 0.035 & 1.000 & 0.00 & 0.00 & 0.00 & 0.00 & 17 & 16.7 \\
\hline FB20\% + Mort $20 \%$ lower $+2 \mathrm{C}+$ high removal + NoQ & 0.013 & -0.091 & 0.064 & 1.000 & 0.00 & 0.00 & 0.00 & 0.00 & 30 & 29.3 \\
\hline FB20\% + Mort $20 \%$ lower $+2 \mathrm{C}+$ high removal $+\mathrm{Q} 30$ & 0.013 & -0.073 & 0.043 & 1.000 & 0.00 & 0.00 & 0.00 & 0.00 & 21 & 20.9 \\
\hline FB20 $\%+$ Mort $20 \%$ lower $+2 \mathrm{C}+$ high removal + Q50 & 0.013 & -0.062 & 0.038 & 1.000 & 0.00 & 0.00 & 0.00 & 0.00 & 16 & 16.3 \\
\hline
\end{tabular}

